\title{
Low dose radiation and cancer in A-bomb survivors: latency and non-linear dose-response in the 1950-90 mortality cohort Greg Dropkin*
}

\author{
Address: Flat 5, 32 Sheil Rd., Liverpool L6 3AE, UK \\ Email: Greg Dropkin* - gregd@gn.apc.org \\ * Corresponding author
}

Published: 18 January 2007

Environmental Health 2007, 6:1 doi:10.1 186/1476-069X-6-1
Received: 30 September 2006

Accepted: 18 January 2007

This article is available from: http://www.ehjournal.net/content/6/I/I

(c) 2007 Dropkin; licensee BioMed Central Ltd.

This is an Open Access article distributed under the terms of the Creative Commons Attribution License (http://creativecommons.org/licenses/by/2.0), which permits unrestricted use, distribution, and reproduction in any medium, provided the original work is properly cited.

\begin{abstract}
Background: Analyses of Japanese A-bomb survivors' cancer mortality risks are used to establish recommended annual dose limits, currently set at I mSv (public) and $20 \mathrm{mSv}$ (occupational). Do radiation doses below $20 \mathrm{mSv}$ have significant impact on cancer mortality in Japanese A-bomb survivors, and is the dose-response linear?
\end{abstract}

Methods: I analyse stomach, liver, lung, colon, uterus, and all-solid cancer mortality in the $0-20$ mSv colon dose subcohort of the 1950-90 (grouped) mortality cohort, by Poisson regression using a time-lagged colon dose to detect latency, while controlling for gender, attained age, and age-atexposure. I compare linear and non-linear models, including one adapted from the cellular bystander effect for $\alpha$ particles.

Results: With a lagged linear model, Excess Relative Risk (ERR) for the liver and all-solid cancers is significantly positive and several orders of magnitude above extrapolations from the Life Span Study Report 12 analysis of the full cohort. Non-linear models are strongly superior to the linear model for the stomach (latency II .89 years), liver (36.90), lung (I3.60) and all-solid (43.86) in fitting the $0-20 \mathrm{mSv}$ data and show significant positive ERR at $0.25 \mathrm{mSv}$ and $10 \mathrm{mSv}$ lagged dose. The slope of the dose-response near zero is several orders of magnitude above the slope at high doses.

Conclusion: The standard linear model applied to the full 1950-90 cohort greatly underestimates the risks at low doses, which are significant when the $0-20 \mathrm{mSv}$ subcohort is modelled with latency. Non-linear models give a much better fit and are compatible with a bystander effect.

\section{Background}

Studies of the Japanese A-bomb survivors cohort have been the key source of radiation risk estimates used to establish environmental and occupational protection standards $[1,2]$ despite the differences between instantaneous exposure in war to gamma and neutron irradiation, and chronic low dose occupational or public exposure in general or to alpha particles. There is an unresolved debate [3] on whether Excess Relative Risk (ERR) increases linearly with dose across a very large range of exposures including the low dose range.

Currently the International Commission on Radiological Protection (ICRP) recommends an annual occupational dose limit of $20 \mathrm{mSv}$ (whole body dose), and many researchers believe that doses below this level have little or no impact on human health. The ICRP risk estimates are strongly based on analyses of the Japanese data for the 
full dose range assuming a linear dose response. On the other hand in the Life Span Study Report 12 (henceforth LSS12) Pierce et al. [4] adopted a linear ERR model for the Japanese data but found some evidence of a non-linear convex dose-response at lower doses for the category of all-solid cancers combined.

Around one third of the data in the 1950-90 mortality cohort analysed in LSS12 concerns persons who received $0-20 \mathrm{mSv}$ instantaneous exposure in 1945. There is no reason to assume any particular relation between dose response in this region and across the entire follow-up. Instead, the low dose data may be analysed in its own right with or without assuming a linear dose response.

In experiments at cell level, low dose radiation induces significant and non-linear effects on micronuclei, chromosome rearrangements and instability, point mutations, and changes in cell cycle protein levels. Studies reviewed by Mothersill and Seymour [5] show low doses have large effects on cells whose nuclei, or even the affected cells themselves, need not be directly traversed by radiation (bystander effects). Some studies find responses rising rapidly with dose and then reaching a plateau. Whilst these early non-linear cellular events may be critical for tumour formation, the human body's defences may also greatly alter the initial dose response or dilute its significance, if the analysed outcome is a cancerous tumour emerging decades later and eventually identified as cause of death.

I analyse the five leading cancer sites (stomach, liver, lung, colon, and uterus) and the grouped category of all-solid cancers in the $0-20 \mathrm{mSv}$ portion of the $1950-90$ Japanese mortality cohort. Follow-up began 5 years after exposure but rather than assume this lag to be optimal, latency is estimated for individual cancers by fitting models which include a variable latent period. I test linearity in the dose response by modelling with two nested non-linear models, each of which contains the linear model.

\section{Methods}

Life Span Study mortality cohort data (1950-1990) were obtained from the Radiation Effects Research Foundation [6] via the Comprehensive Epidemiologic Data Resource [7]. The file r12canc.dat includes anonymous information on a cohort of 86572 survivors, presented as 16612 grouped data cells cross-tabulated by city, sex, total shielded kerma, exposure age and attained age categories, and dose category. Cell data includes a weighted adjusted colon dose, representing an average of individual instantaneous ("flash") doses weighted by person-years within the cell (and assuming neutron Relative Biological Effectiveness RBE $=10$ ). Mean age-at-exposure, mean attained age, and deaths from specific cancers or grouped cancer categories are also shown for each cell. Liver cancer (ICD9 $155(0,1,2))$ includes both deaths attributed to primary liver cancer, and deaths which were not specified as primary or secondary liver cancer. Cancer of the uterus refers to ICD9 180-182, including cervical cancer (ICD9 180).

The data uses the DS86 dosimetry [8], but a limited comparison with the current DS02 dosimetry [9-11] is undertaken.

Subcohorts are defined by restricting weighted adjusted colon dose as given in the cell data. The $0-20 \mathrm{mSv}$ subcohort has 3011 cells comprising 1690391.75 personyears (p-y) observation. This subcohort consists of exactly those cells whose individual members received no more than $20 \mathrm{mSv}$ adjusted colon dose (3009 cells have dose category 1 or 2, while two other cells each contain a single person at risk whose adjusted colon dose was $20 \mathrm{mSv}$ ). Other subcohorts defined below lack such simple interpretation.

Specified cancer deaths in the $\mathrm{i}^{\text {th }}$ cell are assumed to be Poisson distributed with expected value $\lambda_{\mathrm{i}} \mathrm{T}_{\mathrm{i}}$ where $\mathrm{T}_{\mathrm{i}}$ is py observation and $\lambda_{\mathrm{i}}$ depends on control variables and a lagged dose $D_{\phi}$ defined for each cell as weighted adjusted colon dose (in $10 \mathrm{mSv}$ units) if Time-Since-Exposure $\geq \phi$ and 0 otherwise. Time-Since-Exposure $=$ mean attained age - mean age at exposure.

The models below assume

$\lambda=\lambda_{0}(1+\mathrm{ERR})$

$\lambda_{0}=e^{\left(\alpha+\Sigma_{j} \beta_{j} y_{j}\right)}$

where $y_{j}$ are control variables while ERR depends on $D_{\phi}$ and parameters $\theta_{\mathrm{k}}$ (including $\phi$ ) but not on control variables or their parameters.

Gender, log mean attained age, and 14 indicator variables defined by $0 \leq$ age-at-exposure $<5,5 \leq$ age-at-exposure $<$ $10, \ldots$ and $65 \leq$ age-at-exposure $<70$ were used as controls. Indicator variables defined from mean age-at-exposure (cell data) are identical to those defined from the age-atexposure stratification of the dataset. An indicator defined by $70 \leq$ age-at-exposure would be redundant. Log mean attained age was an adequate alternative to the use of attained age categories.

Four models were fitted:

Linear ERR $=\beta \mathrm{D}_{\phi}$

Transient ERR $=\sigma D_{\phi}\left[e^{\left(-\tau D_{\phi}\right)}\right]$ with $\tau \geq 0$ 
Two-phase ERR $=\beta \mathrm{D}_{\phi}+\sigma \mathrm{D}_{\phi}\left[\mathrm{e}^{\left(-\tau \mathrm{D}_{\phi}\right)}\right]$ with $\tau \geq 0$

$$
\text { Category } \mathrm{ERR}=\beta_{1}(\text { dosecat } 1)+\beta_{2}(\text { dosecat } 2)+
$$
$\beta_{3}($ dosecat 3$)$

The usual Linear model is used here with lagged dose. The Control model $(\mathrm{ERR}=0)$ is nested when $\beta=0$.

The Transient model gives an asymptotic linear dose response at very low doses, decaying to zero at higher doses if $\tau>0$. The Linear model is nested when $\tau=0$, while $\sigma=0$ nests the Control model.

The Two-phase model gives an asymptotic linear dose response at very low doses, and a possibly different asymptotic linear response at higher doses, with an exponential transition between the two. The Transient model is nested when $\beta=0$, while $\sigma=0$ (or $\tau=0$ ) nests the Linear model. The Control model is nested when $\beta=\sigma=0$, or when $\tau=0$ and $\beta+\sigma=0$. ERR $\sim \beta \mathrm{D}_{\phi}$ when $\tau \mathrm{D}_{\phi}>>1$, while ERR $\sim(\beta+\sigma) D_{\phi}$ when $\tau D_{\phi}<<1$. The ratio of asymptotic slopes is $\mathbf{R}=1+\sigma / \beta$.

Typical dose-response curves for these three models are shown in Figure 1.

The Category model uses indicator variables defined by cutpoints $0<\gamma_{1}<\gamma_{2}$

dosecat $1=1$ if $0<D_{\phi} \leq \gamma_{1}$ and $=0$ otherwise

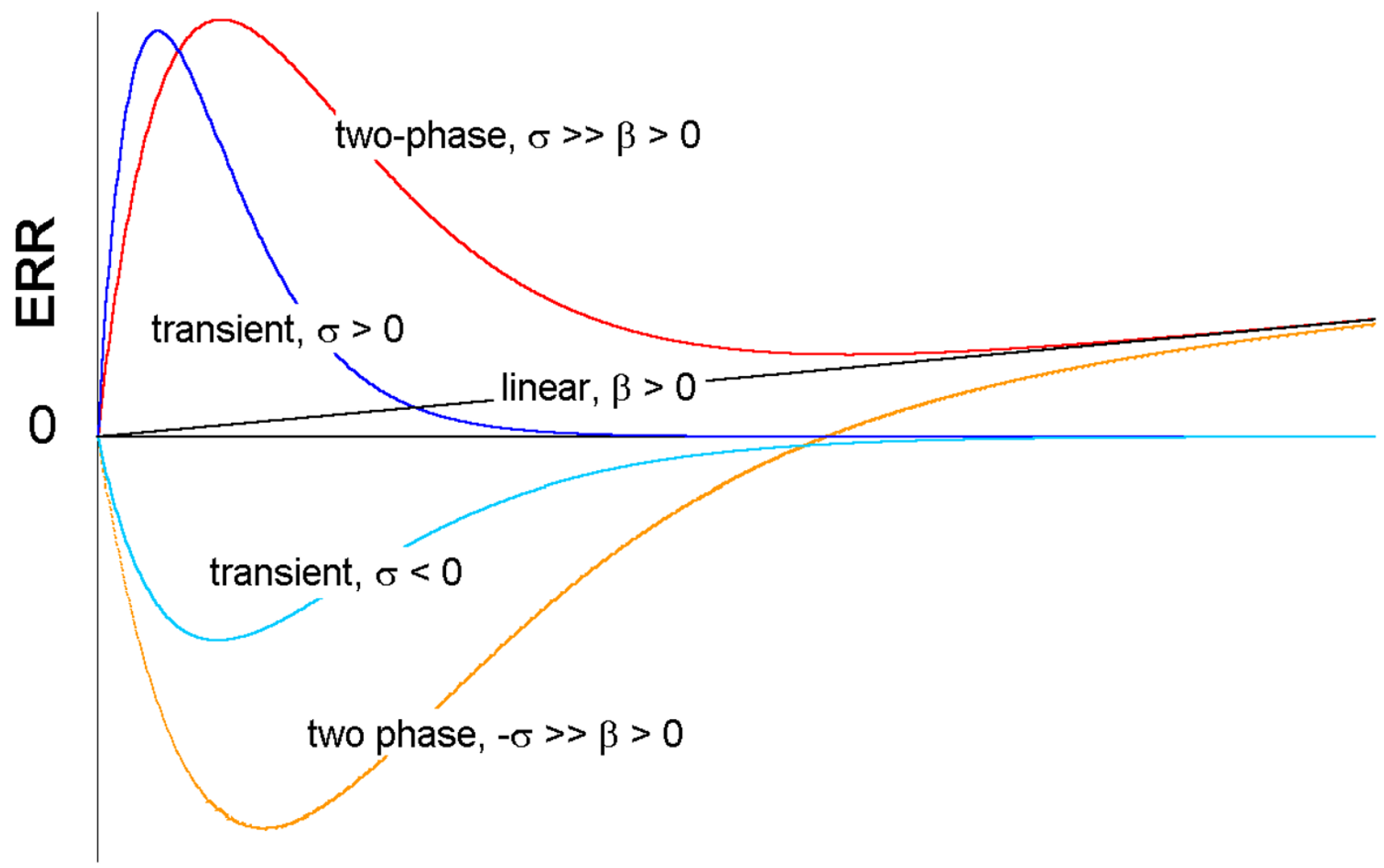

dose

\section{Figure I}

Dose response prototypes for linear, transient, and two-phase models. Typical dose response curves for the linear model ERR $=\beta D$ where ERR is Excess Relative Risk and $D$ is a dose variable (arbitrary units), the transient model ERR $=\sigma D$ e $^{-}$ $\tau D)$, and the two-phase model ERR $=\beta D+\sigma D e^{(-\tau D)}$. Here $\beta, \sigma, \tau$ are parameters with $\tau \geq 0$. The linear model is shown with $\beta$ $>0$. Two versions of the transient model are shown, with $\sigma>0$ and with $\sigma<0$. The transient model converges to 0 as dose $\rightarrow \infty$. Two versions of the two-phase model are shown, with $\sigma>>\beta>0$ and $-\sigma>>\beta>0$; the first version occurs when $\beta>0$ and $\sigma / \beta>\mathrm{e}^{2} \sim 7.39$. Other possibilities (not shown) lack local maxima and minima, but the two-phase model always converges to the linear model as dose $\rightarrow \infty$. 
dosecat $2=1$ if $\gamma_{1}<D_{\phi} \leq \gamma_{2}$ and $=0$ otherwise

dosecat3 $=1$ if $\gamma_{2}<D_{\phi}$ and $=0$ otherwise

The Control model is nested by $\beta_{1}=\beta_{2}=\beta_{3}=0$. $D_{\phi}=0$ also defines the baseline. The model is applied here only with latencies obtained from the two-phase model, and cutpoints $\gamma_{1}=0.025(0.25 \mathrm{mSv}), \gamma_{2}=0.05(0.5 \mathrm{mSv})$ which assign roughly equal p-y to dosecat 1 , dosecat 2 , and dosecat3.

When $\phi=5$ years, dosecat 1 specifies 699 cells $(620850.09$ p-y). Hiroshima data is contained in 544 cells ( 573199.23 p-y), while 155 cells (47650.86 p-y) contain Nagasaki data. Mean attained age ranges from 8.16 years to 96.84 years, and mean age-at-exposure ranges from 1 to 82.99 years. All individual doses within these cells are below 5 $\mathrm{mSv}$. The weighted adjusted colon dose for the cell ranges from $0.004 \mathrm{mSv}$ to $0.25 \mathrm{mSv}$. As $\phi$ increases, cells move to the baseline. For example at $\phi=36.9$ years, dosecat 1 specifies 156 cells (104592.3 p-y) of which 115 cells (95871.94 p-y) refer to Hiroshima and 41 cells (8720.36 p-y) to Nagasaki.

Likewise when $\phi=5$ years, dosecat 2 specifies 560 cells with 519832.84 p-y, of which 109 cells (95907.76 p-y) contain Hiroshima data and 451 cells (423925.08 p-y) contain Nagasaki data. Mean attained age ranges from 8.21 years to 93.32 years and mean age-at-exposure ranges from 0.92 to 84.71 years. All individual doses within these cells are below $5 \mathrm{mSv}$. The weighted adjusted colon dose for the cell ranges from $0.25 \mathrm{mSv}$ to $0.49 \mathrm{mSv}$. At $\phi=36.9$ years, dosecat2 specifies 115 cells (97536.25 p-y) of which 28 cells (21631.85 p-y) refer to Hiroshima and 87 cells (75904.4 p-y) to Nagasaki.

Finally when $\phi=5$ years, dosecat 3 specifies 1579 cells with 548454.05 p-y, of which 780 cells (359098.67 p-y) contain Hiroshima data and 799 cells (189355.38 p-y) contain Nagasaki data. Mean attained age ranges from 8.12 years to 102.2 years and mean age-at-exposure ranges from 0.93 to 91.56 years. All individual doses within these cells are below $20 \mathrm{mSv}$. The weighted adjusted colon dose for the cell ranges from $0.5 \mathrm{mSv}$ to $20 \mathrm{mSv}$. At $\phi=36.9$ years, dosecat3 specifies 353 cells (97629.42 p-y) of which 176 cells (63005.21 p-y) refer to Hiroshima and 177 cells (34624.21 p-y) to Nagasaki.

Note that whilst the dosecat variables are well defined on the cells, they have no simple interpretation in terms of individual doses within those cells. A cell with $\mathrm{D}_{\phi} \leq 0.025$ ( $0.25 \mathrm{mSv}$ ) may contain individuals with lagged doses up to $5 \mathrm{mSv}$; it is only the weighted average which is constrained below $0.25 \mathrm{mSv}$.
Each model is also constrained by $\lambda=\lambda_{0}(1+$ ERR $) \geq 0$ (equivalently ERR $\geq-1$ ) in all cells, as the Poisson distribution is undefined if $\lambda_{\mathrm{i}} \mathrm{T}_{\mathrm{i}}<0$.

Poisson regression [12] is based on minimising the model Deviance, or equivalently minimising $\Sigma_{\mathrm{i}}\left[\mathrm{E}_{\mathrm{i}}-\mathrm{O}_{\mathrm{i}} \ln \left(\mathrm{E}_{\mathrm{i}}\right)\right]$ where $\mathrm{E}_{\mathrm{i}}$ and $\mathrm{O}_{\mathrm{i}}$ are the expected and observed values.in each cell. While $\mathrm{O}_{\mathrm{i}}$ is given by the data, $\mathrm{E}_{\mathrm{i}}$ depends on the model and its parameter values. The data were placed on a spreadsheet and the Excel tool Solver (Newton-Raphson iteration) was used to optimise the parameters subject to defined constraints.

With the control model, the minimal Deviance is independent of $\phi$. Once $\phi$ is fixed, the linear model has a unique minimum Deviance. With other models, local minima were compared to find the absolute minimum $\operatorname{DevMod}_{\phi}$. Searches were conducted by partitioning the $\tau$ axis as $[0,1],[1,2] \ldots\left[2^{j-1}, 2^{j}\right] \ldots\left[2^{8}, 2^{9}\right],\left[2^{9}, \infty\right)$ and beginning iteration from $\left(\mathrm{C}, 0,0, \tau_{\mathrm{j}}\right)$ where $\mathrm{C}$ represents the control model Maximum Likelihood Estimate parameter values, $\beta$ and $\sigma$ are initially set to 0 ( $\beta$ is constrained to 0 for the transient model); while $\tau_{\mathrm{j}}$ is constrained to the $\mathrm{j}^{\text {th }}$ interval.

If model $I$ is nested within model $J$ by k parameter constraints, the likelihood ratio test for comparing the two models at $\phi, \mathrm{LRT}_{J-I, \phi}=\operatorname{DevMod}_{I, \phi}-\operatorname{DevMod}_{I, \phi}$ is approximately $\chi^{2}$ distributed on $\mathrm{k} \mathrm{df}$. At a given $\phi, \mathrm{LRT}_{\text {lin-con }}$ and $\mathrm{LRT}_{\text {trans-con }}$ for comparing the linear and transient models with the control model each have $1 \mathrm{df}$, while $\mathrm{LRT}_{2 \mathrm{p} \text {-con }}$ for comparing the two-phase model with the control model has $2 \mathrm{df}$. Note that $\mathrm{LRT}_{2 \mathrm{p} \text {-trans' }} \mathrm{LRT}_{2 \mathrm{p}-\mathrm{lin}}$ and $\mathrm{LRT}_{\text {trans-lin }}$ have $1 \mathrm{df}$ as each nested pair is defined by a single parameter constraint, and that $\mathrm{LRT}_{2 \mathrm{p} \text {-con }}=\mathrm{LRT}_{2 \mathrm{p} \text {-lin }}+\mathrm{LRT}_{\text {lin-con }}$.

For each model $J$ (linear, transient, and two-phase), I found best fits by choosing $\phi=\phi_{\mathrm{m}}$ to maximise $\mathrm{LRT}_{\text {J-con, } \phi}$ (equivalently to minimise DevMod ${ }_{J, \phi}$ ) either absolutely or with the constraint that ERR at $\mathrm{D}_{\phi}=0.025$ be $\geq 0$. The value of $\phi_{\mathrm{m}}$ may vary with the model.

Profile Likelihood Confidence Intervals for ERR were computed at specified values of $D_{\phi}$. For example, in the two-phase model ERR depends on $\mathrm{D}_{\phi}$ and $\mathrm{T}=(\beta, \sigma, \tau)$ whilst Deviance depends on $(\phi, C, T)$ where $C$ is the vector of control parameters. With $\phi$ fixed, let $\mathrm{V}_{\phi}$ be the set of $\mathrm{T}$ which can be ruled out with $95 \%$ confidence, as all choices of C give $\operatorname{Dev}(\phi, C, T)-\operatorname{DevMod}_{\phi}>\mathrm{K}$, where $\mathrm{K}$ 7.8147 satisfies $\chi_{3}^{2}(K)=0.95$. Define $\operatorname{Min}_{\phi}$ (respectively $\operatorname{Max}_{\phi}$ ) as the largest $\mathrm{v}$ (smallest $\mathrm{w}$ ) for which the constraint $\operatorname{ERR}\left(\mathrm{D}_{\phi^{\prime}} \mathrm{T}\right)<\mathrm{v}(>\mathrm{w})$ implies $\mathrm{T} \in \mathrm{V}_{\phi}$. The interval $\left(\mathrm{Min}_{\phi^{\prime}}\right.$ $\operatorname{Max}_{\phi}$ ) is taken as a $95 \%$ CI for $\operatorname{ERR}\left(D_{\phi}\right)$ in the two-phase model. 


\section{Results}

For each cancer site and for $\phi=5,6, \ldots 44$, models were fitted to the $0-20 \mathrm{mSv}$ male/female $(\mathrm{M} / \mathrm{F})$ data.

For the linear model only, I estimated $\mathrm{ERR}_{0.025, \phi}$ by fitting the model to the restricted subcohort of cells with mean weighted adjusted colon dose $\leq 0.5 \mathrm{mSv}$; $\mathrm{ERR}_{1, \phi}$ was obtained from fitting the $0-20 \mathrm{mSv}$ data, as with all other modelling.

More precise optimal latencies $\phi_{\mathrm{m}^{\prime}} \quad 95 \%$ CI's for $\mathrm{ERR}_{0.025, \phi_{\mathrm{m}}}$ and $\mathrm{ERR}_{1, \phi_{\mathrm{m}}}$, and Goodness-of-Fit (GoF) statistics were determined for the nested models, including separate male and female results. The category model $(\mathrm{M} / \mathrm{F})$ was then fitted using the optimal latencies from the two-phase model.

Results are now outlined for specific cancers (M/F).

\section{Stomach}

The linear model is never significant against the control model, but Figure 2 suggests two distinct latency periods: $5 \leq \phi \leq 21$, and $29 \leq \phi \leq 41$. Outside these periods, the nested models show no significant improvement on the control model. In both periods, the two-phase and transient models improve on the control model. The twophase model significantly improves on the transient and linear models when $5 \leq \phi \leq 21$ and on the linear model when $29 \leq \phi \leq 41$. For the two-phase model, $\mathrm{ERR}_{0.025, \phi}$ and $\mathrm{ERR}_{1, \phi}$ are both positive when $5 \leq \phi \leq 21$, and negative when $29 \leq \phi \leq 41$ (Figure 3).

For the linear model (Table 1) $\phi_{\mathrm{m}}=6.66$ is optimal in the region of $E R R \geq 0$, but the model is not significant against the control model. For the transient model (Table 2) $\phi_{\mathrm{m}}=$ 11.85 is optimal within the range for which $\mathrm{ERR}_{0.025, \phi} \geq 0$, but ERR is not significantly positive. The optimal latency for the two-phase model (Table 3 ) is $\phi_{\mathrm{m}}=11.89$, when comparison with the control model has $\mathrm{LRT}_{2 \mathrm{p} \text {-con }}=21.190$ (2 df), and comparisons with the transient and linear models have LRT $_{2 \mathrm{p} \text {-trans }}=15.684(1 \mathrm{df})$ and LRT $_{2 \mathrm{p} \text {-lin }}=$ 19.643 ( $1 \mathrm{df}$ ). Each LRT is highly significant. The twophase model gives $\mathrm{ERR}_{0.025, \phi}=0.391$ with $95 \% \mathrm{CI}(0.077$, $0.857)$ while $\operatorname{ERR}_{1, \phi}=0.459(0.113,0.942)$. When $\mathrm{D}_{\phi}=$ Dmax $=0.012$, ERR attains a local maximum of 0.539 $(0.171,1.037)$.

Applying the category model (Table 4) with $\phi=11.89$ gives LRTcat-con $=21.590(3 \mathrm{df})$ and both $\beta 1$ and $\beta 3$ are significantly positive.

The models pass Goodness-of-Fit tests with Dev, but Pearson Chi-Square exceeds df due to one case in a cell with $\mathrm{T}$ $=0.4 \mathrm{p}-\mathrm{y}$. The two-phase model is preferable to its nested alternatives by LRT comparisons, and clearly distinguishes the latency periods as regions of positive and negative ERR. At the optimal latency, $R=1+\sigma / \beta=262.62$.

\section{Liver}

There are two distinct latency periods outside which the models are insignificant (Figure 4). When $10 \leq \phi \leq 23$ the two-phase model improves on the transient, linear, and control models, and $\mathrm{ERR}_{0.025, \phi}$ and $\mathrm{ERR}_{1, \phi}$ are negative in all three models (Figure 5). When $32 \leq \phi \leq 41$ the twophase model improves on the transient, linear, and control models, and $\mathrm{ERR}_{0.025, \phi}$ and $\mathrm{ERR}_{1, \phi}$ are non-negative in all three models. When $34 \leq \phi \leq 43$ the transient and linear models each improve on the control model with positive ERR, and when $34 \leq \phi \leq 38$ the transient improves on the linear model.

The optimal latencies are 38.58 (linear), 36.90 (transient), and 36.90 if the two-phase model is optimised with $\mathrm{ERR}_{0.025, \phi} \geq 0$. At $\phi_{\mathrm{m}}=36.90$ the two-phase model has $\mathrm{LRT}_{2 \mathrm{p} \text {-con }}=34.874$ while $\mathrm{LRT}_{2 \mathrm{p} \text {-trans }}=16.755$ and $\mathrm{LRT}_{2 \mathrm{p} \text {-lin }}$ $=27.642$, all highly significant comparisons. At the optimal latency, the two-phase model gives $\mathrm{ERR}_{0.025, \phi}=1.099$ $(0.264,2.374)$ while $\mathrm{ERR}_{1, \phi}=1.428(0.481,2.954)$. The local maximum ERR occurs when $\mathrm{D}_{\phi}=0.013$. Estimates from the transient and linear models are comparable.

Applying the category model with $\phi=36.90$ gives LRT $_{\text {cat }}$ con $=33.844$ and $\beta_{1}, \beta_{2}$, and $\beta_{3}$ are all significantly positive. If "city" is included as a control, LRT $_{\text {cat-con }}=34.939, \beta_{1}=$ $1.35(0.72,2.23), \beta_{2}=0.73(0.14,1.60), \beta_{3}=1.39(0.70$, 2.34).

The models pass both GoF tests. The two-phase model is preferable to its nested alternatives by LRT and gives wider periods of significant improvement on the control model, distinguished as regions of positive and negative ERR. At the optimal latency $\mathbf{R}=204.11$.

\section{Lung}

The linear model is never significant against the control model (Figure 6). The transient improves on the linear and control models when $5 \leq \phi \leq 38$. The two-phase improves on the linear and control models when $5 \leq \phi \leq$ 21 and when $24 \leq \phi \leq 38$, and on the transient model when $32 \leq \phi \leq 38$. When $5 \leq \phi \leq 21$ the transient and linear models give positive $\mathrm{ERR}_{0.025, \phi}$ and $\mathrm{ERR}_{1, \phi}$ (Figure 7) as does the two-phase when $7 \leq \phi \leq 21$. When $22 \leq \phi \leq 41$ $\mathrm{ERR}_{0.025, \phi}$ and $\mathrm{ERR}_{1, \phi}$ are negative in the two-phase and transient models.

Optimal latencies are 16.90 (linear), 13.60 (transient), and 13.60 if the two-phase model is optimised with positive $\mathrm{ERR}_{0.025}$. At $\phi_{\mathrm{m}}=13.60$ the transient model has LRTtrans-con $=15.701$ while LRT $_{\text {trans-lin }}=14.394$, both highly 


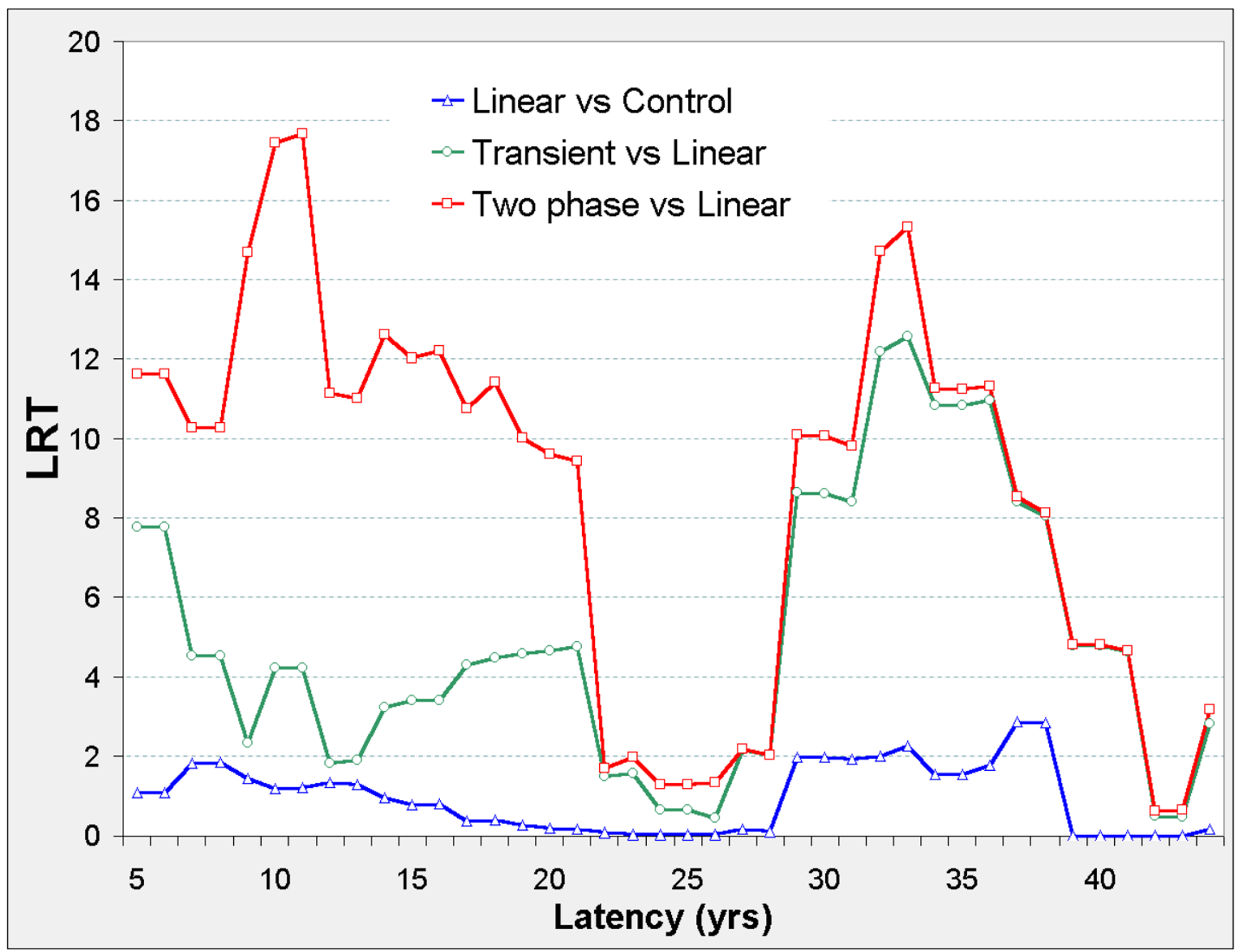

\section{Figure 2}

Stomach cancer mortality in $\mathbf{0}-20 \mathrm{mSv}$ subcohort, LRT vs latency. LRT is the likelihood ratio test for comparison of the indicated pair of models evaluated at fixed latency $\phi$, and is $\chi^{2}$ distributed on I d.f. (red line shows $L_{R T}$ pp-lin $_{\text {for comparing }}$ the two-phase and linear models, green line shows LRT trans-lin for comparing transient and linear models, blue line shows LRT linfor comparing linear and control models) LRT values above 3.84 are significant at $p=0.05$, above 6.63 at $p=0.01$, above 10.83 at $p=0.001$. Other LRT can be derived at each $\phi$ value, e.g. $\mathrm{LRT}_{2 \mathrm{p} \text {-con }}=\mathrm{LRT}_{2 \mathrm{p} \text {-lin }}+\mathrm{LRT}_{\text {lin-con }}$ and $\mathrm{LRT}_{\text {trans-con }}=\mathrm{LRT}_{\text {trans-lin }}$

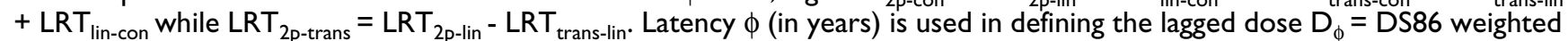
adjusted colon dose if Time-Since-Exposure $\geq \phi, D_{\phi}=0$ otherwise. Models specify the Excess Relative Risk ERR as a function of $D_{\phi}$ while controlling for gender, log attained age, and age-at-exposure categories. Control: $E R R=0$ Linear: $E R R=\beta D_{\phi}$; control model nested by $\beta=0$. Transient: $E R R=\sigma D_{\phi} \mathrm{e}^{(-\tau D \phi)}$ with $\tau \geq 0$; linear model nested by $\tau=0$. Two-phase: $E R R=\beta D_{\phi}+\sigma D_{\phi} \mathrm{e}^{(-}$ $\tau \mathrm{D} \phi)$ with $\tau \geq 0$; linear model nested by $\sigma=0$; transient model nested by $\beta=0$.

significant. At this latency the transient model gives $\mathrm{ERR}_{0.025, \phi}=0.790(0.195,2.006)$ while $\mathrm{ERR}_{1, \phi}=0.796$ $(0.189,1.985)$. The two-phase model does not improve the transient and gives comparable ERR with somewhat wider CI's. It does improve on the linear model with $\mathrm{LRT}_{2 \mathrm{p}-\mathrm{lin}}=14.734$ and gives $\mathbf{R}=86.39$.

Applying the category model with $\phi=13.60$ gives $\mathrm{LRT}_{\text {cat- }}$ con $=19.304$ and $\beta_{1}, \beta_{2}$, and $\beta_{3}$ are all significantly positive.
The 3 nested models pass both GoF tests. The transient model is preferable here.

\section{Colon}

None of the models give significant positive response for the M/F data (Figure 8, Figure 9). The transient model has occasional weak negative response. 


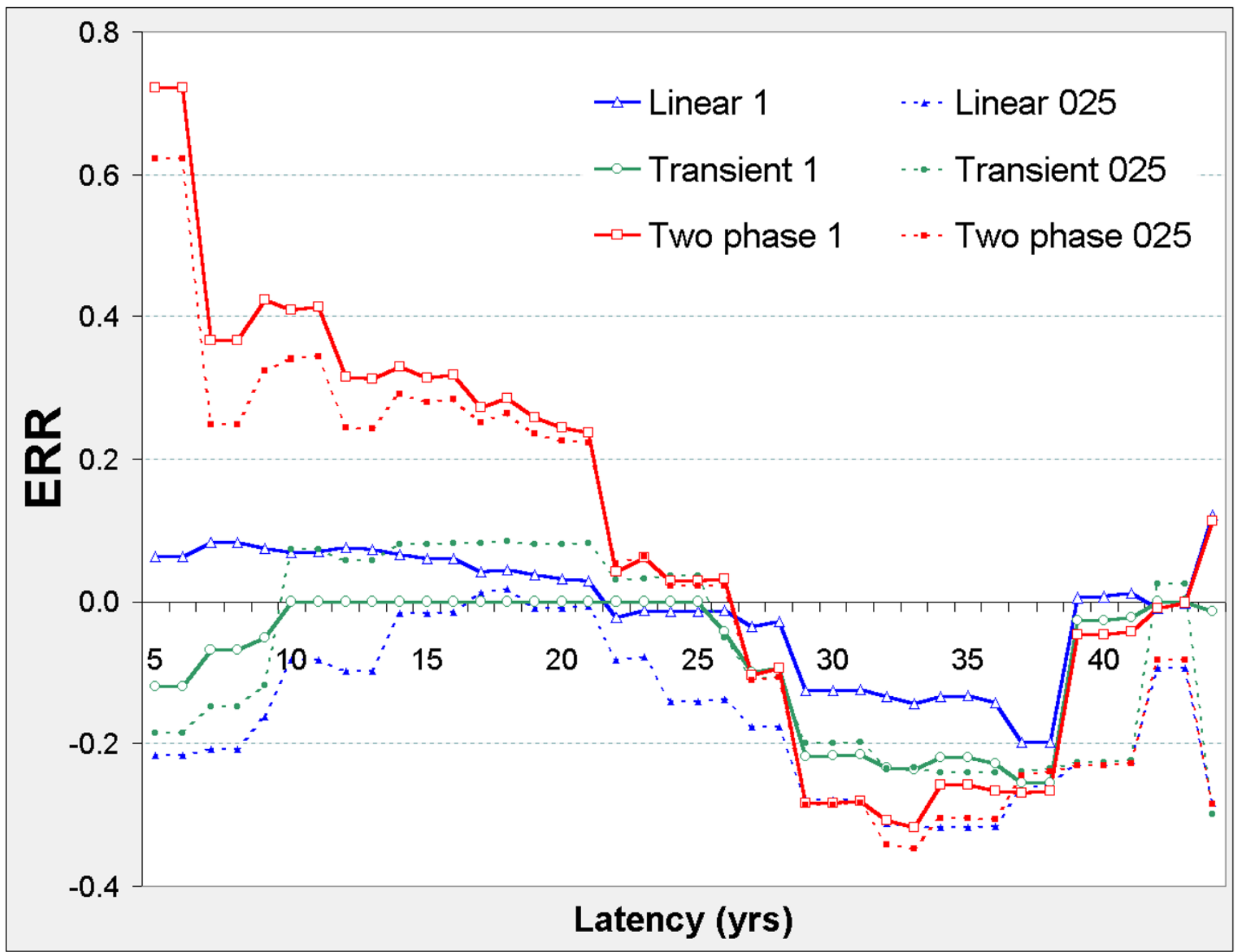

Figure 3

Stomach cancer mortality in 0 - 20 mSv subcohort, ERR vs latency. For each model (two-phase in red, transient in green, linear in blue) fitted at fixed latency $\phi$, series I (solid lines) shows the Excess Relative Risk ERR , (ERR at I0 mSv lagged dose); series 025 (dotted lines) shows $E R_{0.025}$ (ERR at $0.25 \mathrm{mSv}$ lagged dose). For latency $\phi$ and model definitions see Figure 2. For Linear 025 only, $\mathrm{ERR}_{0.025}$ is estimated from the $0-0.5 \mathrm{mSv}$ data.

\section{Uterus}

The linear model is never significant against the control model (Figure 10). When $12 \leq \phi \leq 16$ the transient and two-phase models both improve on the control model, and ERR is negative in all three models (Figure 11). When $24 \leq \phi \leq 33 \mathrm{ERR}_{0.025, \phi}$ and $\mathrm{ERR}_{1, \phi}$ are positive in the twophase and transient models. At the optimal latency $\phi=$ 26.91 (in the region of positive ERR) both the two-phase and transient models are weakly significant against the linear and control models. The 95\%CI's do not exclude negative ERR.

Applying the category model with $\phi=26.91$ gives the weak result $\mathrm{LRT}_{\text {cat-con }}=8.077$ with only $\beta_{1}$ significantly positive.

\section{All-solid}

When $22 \leq \phi \leq 23$ the two-phase model is significant against transient, linear, and control models (Figure 12) and ERR is negative in all models (Figure 13). When $39 \leq$ $\phi \leq 44$ the transient model improves on the control model, and when $42 \leq \phi \leq 43$ the transient and two-phase improve on the linear and control models. When $37 \leq \phi \leq$ 44 ERR is positive in all models. The optimal latency in all three nested models is $\phi_{\mathrm{m}}=43.86$, at which all are significant against the control model and the transient and twophase are significant against the linear model.

At $\phi_{\mathrm{m}}=43.86$ the transient model has $\mathrm{LRT}_{\text {trans-con }}=16.781$ and LRT $_{\text {trans-lin }}=11.753$, both highly significant, with $\mathrm{ERR}_{0.025, \phi}=0.271(0.070,0.509)$ while $\mathrm{ERR}_{1, \phi}=0.300$ 
Table I: Linear model ${ }^{a}$

\begin{tabular}{|c|c|c|c|}
\hline & Stomach & Liver & Lung \\
\hline gender & $M / F$ & $M / F$ & $M / F$ \\
\hline cases $^{b}$ & 1482 & 540 & 524 \\
\hline$\phi_{m}^{c}$ & 6.66 & 38.58 & 16.90 \\
\hline ca $D_{\phi}>0^{d}$ & 1412 & 172 & 494 \\
\hline $\mathbf{L R T}_{\text {lin-con }}^{e}$ & 2.09 & 11.21 & 2.26 \\
\hline $\mathbf{E R R}_{\mathbf{l}, \phi} \mathrm{fg}_{\mathrm{g}}$ & $0.09(-0.03,0.22)$ & $0.69(0.25,1.26)$ & $0.16(-0.05,0.42)$ \\
\hline $\mathbf{D e v}^{h}$ & 1680.64 & 1258.02 & 1052.43 \\
\hline Chi-sq ${ }^{i}$ & 3205.08 & 2389.85 & 2500.37 \\
\hline df & 2992 & 2992 & 2992 \\
\hline \multirow[t]{2}{*}{ Excess $^{k}$} & 38.13 & 27.17 & 23.20 \\
\hline & Colon & Uterus & All solid \\
\hline gender & $M / F$ & $\mathrm{~F}$ & $M / F$ \\
\hline cases $^{b}$ & 214 & 263 & 4379 \\
\hline$\phi_{\mathrm{m}}^{c}$ & 43.91 & 6.12 & 43.86 \\
\hline ca $\mathbf{D}_{\phi}>0$ & 33 & 262 & 365 \\
\hline $\mathbf{L R T}_{\text {lin-con }}{ }^{\mathrm{e}}$ & 0.19 & 0.51 & 5.03 \\
\hline $\mathbf{E R R}_{\mathbf{l}, \phi}$ fg & $0.17(-0.44,1.17)$ & $0.10(-0.16,0.44)$ & $0.26(0.03,0.52)$ \\
\hline Dev $^{h}$ & 719.80 & 638.46 & 2133.03 \\
\hline Chi-sqi & 3497.50 & 1010.56 & 2769.51 \\
\hline df & 2992 & 1513 & 2992 \\
\hline Excess $^{k}$ & 1.51 & 8.88 & 25.01 \\
\hline
\end{tabular}

${ }^{a} 0-20 \mathrm{mSv}$ subcohort, Excess Relative Risk ERR $=\beta \mathrm{D}_{\phi}$ with $\beta$ constrained by I + ERR $\geq 0$ for all data cells. $\mathrm{D}_{\phi}$ is the weighted adjusted colon dose (neutron RBE $=10$ ), lagged by $\phi$ years, in $10 \mathrm{mSv}$ units. The control model is nested by $\beta=0$.

$b$ deaths in the subcohort from the specified cancer

c Latency $\phi_{\mathrm{m}}$ is chosen in the range $5-44$ years. to minimise linear model Deviance for the given cancer site and gender. Where italicised, $\phi_{\mathrm{m}}$

minimises Dev subject to ERR $\geq 0$, equivalent to $\beta \geq 0$

${ }^{d}$ deaths in the subcohort from the specified cancer, for which $D_{\phi}>0$ where $\phi=\phi_{m}$

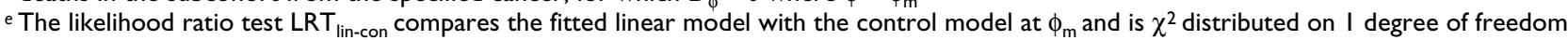

$f$ ERR $_{I, \phi}$ is the Excess Relative Risk at $D_{\phi}=I$ with $\phi=\phi_{\mathrm{m}}$

$g$ 95\% Profile Likelihood Confidence Intervals are calculated with $\phi$ fixed at $\phi_{\mathrm{m}}$

$h$ Deviance of the fitted model

i Pearson Chi-Square of the fitted model

$j$ Degrees of Freedom of the fitted model

${ }^{k}$ difference between Observed (= Expected) cases and the number expected if $D_{\phi}$ is set to 0 in every cell after fitting the model

$(0.034,0.633)$. The two-phase model has $\mathrm{LRT}_{2 \mathrm{p}-\mathrm{con}}=$ 17.925, $\mathrm{LRT}_{2 \mathrm{p}-\text { lin }}=12.896$, both highly significant, while $\mathrm{LRT}_{2 \mathrm{p} \text {-trans }}=1.143$ is not significant. $\mathrm{ERR}_{0.025, \phi}=0.269$ $(0.051,0.538)$ while $\mathrm{ERR}_{1, \phi}=0.272(-0.044,0.662)$. The linear model has $\mathrm{LRT}_{\text {lin-con }}=5.029$ and $\mathrm{ERR}_{1, \phi}=0.259$ $(0.030,0.522)$. If applied to the $0-0.5 \mathrm{mSv}$ data, the optimal latency is $\phi_{\mathrm{m}}=41.78$ at which $\mathrm{LRT}_{\text {lin-con }}=5.562$ and $\mathrm{ERR}_{0.025, \phi}=0.175(0.028,0.344)$.

At $\phi=43.86$ the category model has LRT $_{\text {cat-con }}=16.311$ while $\beta_{2}$ and $\beta_{3}$ are significantly positive.

The models pass both GoF tests. The transient model is preferable here, for simplicity.

\section{Comparison with LSSI2}

The ERR values found here by applying non-linear models to the $0-20 \mathrm{mSv}$ subcohort and optimising latency are several orders of magnitude above those derived by extrapolating from results for a linear model applied with fixed 5 year lag to the entire dose range of A-bomb survivors, as in LSS12 [4] whose Tables AII (Male/Female), AIII (Male) and AIV (Female) show ERR/Sv (organ dose). If a linear model is applied to a single dataset, ERR for $\mathrm{d} \mathrm{mSv}$ will be (d/1000)(ERR/Sv). Extrapolations of this type are inherent in the ICRP estimate of the risks arising from low doses, which underpin its recommended annual dose limits.

Comparisons are shown in Table 5. Significant discrepancies occur at $10 \mathrm{mSv}\left(\mathrm{ERR}_{1}\right)$ and $0.25 \mathrm{mSv}\left(\mathrm{ERR}_{0.025}\right)$ with the two-phase model for stomach, liver, and lung; and with the transient model for liver and lung. 
Table 2: Transient model ${ }^{a}$

\begin{tabular}{|c|c|c|c|}
\hline & Stomach & Liver & Lung \\
\hline gen & $M / F$ & $M / F$ & $M / F$ \\
\hline$\phi_{\mathbf{m}}^{b}$ & 11.85 & 36.90 & 13.60 \\
\hline ca $D_{\phi}>0$ & 1323 & 231 & 506 \\
\hline$\sigma^{c}$ & 77.56 & 33.51 & 34.72 \\
\hline$\tau$ & 129.19 & 3.56 & 3.78 \\
\hline $\mathbf{L R T}_{\text {trans-lin }}{ }^{d}$ & 4.49 & 10.89 & 14.39 \\
\hline LRT $_{\text {trans-con }}$ & 5.91 & 18.12 & 15.70 \\
\hline $\mathbf{E R R}_{0.025, \phi} \mathrm{e}^{\mathrm{e}}$ & $0.08(-0.11,0.23)$ & $0.77(0.18,1.67)$ & $0.79(0.20,2.01)$ \\
\hline $\mathbf{E R R}_{\mathrm{I}, \phi}$ & $0.00(-0.06,0.16)$ & $0.95(0.28,1.99)$ & $0.80(0.19,1.99)$ \\
\hline Dmax $f$ & 0.01 & 0.28 & 0.27 \\
\hline $\mathbf{E R R}_{\mathrm{Dmax}, \phi}$ & $0.22(-0.04,0.61)$ & $3.46(1.00,7.11)$ & $3.38(0.90,8.43)$ \\
\hline Dev & 1676.81 & 1251.10 & 1039.00 \\
\hline Chi-sq & 3397.32 & 2436.33 & 2728.08 \\
\hline df & 2991 & 2991 & 2991 \\
\hline \multirow[t]{2}{*}{ Excess } & 91.23 & 95.89 & 214.39 \\
\hline & Colon & Uterus & All solid \\
\hline gen & $M / F$ & $\mathrm{~F}$ & $M / F$ \\
\hline$\phi_{\mathbf{m}}^{b}$ & 43.98 & 26.91 & 43.86 \\
\hline ca $D_{\phi}>0$ & 28 & 127 & 365 \\
\hline$\sigma^{c}$ & 26.69 & 275.88 & 11.89 \\
\hline$\tau$ & 5.98 & 132.36 & 3.68 \\
\hline $\mathbf{L R} \mathbf{T}_{\text {trans-lin }}{ }^{d}$ & 3.17 & 4.48 & 11.75 \\
\hline LRT $_{\text {trans-con }}$ & 3.20 & 4.48 & 16.78 \\
\hline $\mathbf{E R R}_{0.025, \phi}{ }^{\mathrm{e}}$ & $0.58(-0.25,1.85)$ & $0.25(-0.09,1.13)$ & $0.27(0.07,0.5 \mathrm{I})$ \\
\hline $\mathbf{E R R}_{\mathrm{I}, \phi}$ & $0.07(-0.49, \mathrm{I} .7 \mathrm{I})$ & $0.00(-0.23,1.06)$ & $0.30(0.03,0.63)$ \\
\hline $\operatorname{Dmax}^{f}$ & 0.17 & 0.01 & 0.27 \\
\hline $\mathbf{E R R}_{\mathrm{Dmax}, \phi}$ & $1.64(-0.60,6.10)$ & $0.77(-0.54,5.35)$ & $1.19(0.41,2.06)$ \\
\hline Dev & 716.79 & 634.49 & 2121.27 \\
\hline Chi-sq & 3473.93 & 1051.37 & 2765.95 \\
\hline df & 2991 & 1512 & 2991 \\
\hline Excess & 8.24 & 19.99 & 78.00 \\
\hline
\end{tabular}

${ }^{a} 0-20 \mathrm{mSv}$ subcohort, Excess Relative Risk ERR $=\sigma D_{\phi} e^{\left(-\tau D_{\phi}\right)}$ with $\tau \geq 0$ and $\sigma, \tau$ constrained by I + ERR $\geq 0$ for all data cells; for $D_{\phi}$ see Table I. The linear model is nested by $\tau=0$; the control model is nested by $\sigma=0$.

${ }^{b}$ chosen in the range $5-44$ years. to minimise transient model Deviance; where italicised $\phi_{m}$ minimises Dev subject to ERR $\geq 0$, equivalent to $\sigma \geq 0$. 'At $\phi_{m}, \sigma$ and $\tau$ are the fitted Maximum Likelihood Estimate parameter values.

${ }^{d}$ At $\phi_{m}$, the likelihood ratio test LRT trans-lin compares the transient with the linear model and LRT $T_{\text {trans-con }}$ compares the transient model with the control model. Each LRT is $\chi^{2}$ distributed on I degree of freedom.

e At $\phi_{m}$, ERR $R_{D, \phi}$ is the Excess Relative Risk at $D_{\phi}=D$, with $95 \%$ Profile Likelihood Confidence Interval.

$f$ At $\phi_{m}, D$ max $=1 / \tau$ is the value of $D$ which maximises $E R R_{D, \phi}$

$\mathrm{g} / \mathrm{a}$ indicates no lower limit could be calculated with I + ERR $\geq 0$

Other definitions and total cases as Table I.

Estimates of $\mathrm{ERR}_{1}$ from the non-linear models are 2 to 3 orders of magnitude above extrapolations from LSS12; for $\mathrm{ERR}_{0.025}$ the discrepancy is 3 to 4 orders of magnitude.

\section{Dosimetry}

As a first step towards understanding how dosimetry errors may affect these results, the models were fitted to portions of the $0-20 \mathrm{mSv}$ data for the liver. Models were refined to control for "city", although this had little impact. There are 173 data cells with weighted adjusted colon dose $=0$. If these cells are deleted from the $0-20$ $\mathrm{mSv}$ subcohort and analysis is restricted to the remaining 2838 cells, fitting the two-phase and linear models for the liver $(\mathrm{M} / \mathrm{F})$ at $\phi=36.90$ years gives $\mathrm{LRT}_{2 \mathrm{p} \text {-con }}=37.639$, $\mathrm{LRT}_{2 \mathrm{p}-\mathrm{lin}}=30.095$, and $\mathrm{ERR}_{1}=1.478(0.52,3.04)$. Thus the results for the liver are not caused by any special features of the zero-dose cells.

Alternatively, choose $0=\mathrm{x}_{0}<\mathrm{x}_{1}<\mathrm{x}_{2}<\ldots<\mathrm{x}_{9}<\mathrm{x}_{10}=20$ $\mathrm{mSv}$. Define $\mathrm{S}_{\mathrm{i}}$ as the set of data cells in the $0-20 \mathrm{mSv}$ 
Table 3: Two-phase model ${ }^{a}$

\begin{tabular}{|c|c|c|c|}
\hline & Stomach & Liver & Lung \\
\hline gen & $M / F$ & $M / F$ & $M / F$ \\
\hline$\phi_{m}^{b}$ & 11.89 & 36.90 & 13.60 \\
\hline ca $D_{\phi}>0$ & $131 \mid$ & 231 & 506 \\
\hline$\beta^{c}$ & 0.46 & 1.43 & 0.44 \\
\hline$\sigma$ & 119.96 & 290.09 & 37.92 \\
\hline$\tau$ & 82.67 & 76.82 & 4.47 \\
\hline $\mathbf{L R T}_{\text {2p-trans }}{ }^{d}$ & 15.68 & 16.76 & 0.34 \\
\hline $\mathbf{L R T}_{2 p-\operatorname{lin}}$ & 19.64 & 27.64 & 14.73 \\
\hline LRT $_{2 p-c o n}$ & 21.19 & 34.87 & 16.04 \\
\hline $\mathbf{E R R}_{0.025, \phi}$ & $0.39(0.08,0.86)$ & $1.10(0.26,2.37)$ & $0.86(0.14,3.34)$ \\
\hline $\mathbf{E R R}_{\mathrm{l}, \phi}$ & $0.46(0.11,0.94)$ & $1.43(0.48,2.95)$ & $0.88(0.12,3.36)$ \\
\hline$D_{\max }$ & 0.01 & 0.01 & 0.23 \\
\hline $\mathbf{E R R}_{\mathrm{Dmax}, \phi}$ & $0.54(0.17,1.04)$ & I.4I $(0.50,2.86)$ & $3.23(0.09,9.39)$ \\
\hline Dev & 1661.53 & 1234.35 & 1038.66 \\
\hline Chi-sq & 3408.01 & 2447.95 & 2770.40 \\
\hline df & 2990 & 2990 & 2990 \\
\hline $\mathbf{R}^{f}$ & 262.62 & 204.11 & 86.39 \\
\hline \multirow[t]{2}{*}{ Excess } & 390.00 & 126.36 & 224.43 \\
\hline & Colon & Uterus & All Solid \\
\hline gen & $M / F$ & $\mathrm{~F}$ & $M / F$ \\
\hline$\phi_{m}^{b}$ & 20.28 & 26.91 & 43.86 \\
\hline $\mathbf{D}_{\phi}>0$ & 184 & 127 & 365 \\
\hline$\beta^{c}$ & -0.74 & 0.47 & -0.62 \\
\hline$\sigma$ & 11.32 & 198.10 & 13.10 \\
\hline$\tau$ & 2.66 & 81.12 & 2.32 \\
\hline $\mathbf{L R T}_{\text {2p-trans }}{ }^{d}$ & 1.32 & 1.83 & 1.14 \\
\hline $\mathbf{L R T}_{2 p-\operatorname{lin}}^{2 p}$ & 3.01 & 6.31 & 12.90 \\
\hline LRT $_{2 p-c o n}$ & 3.54 & 6.31 & 17.93 \\
\hline $\mathbf{E R R}_{0.025, \phi}$ & $0.25(-0.44,1.46)$ & $0.66(-0.10,2.44)$ & $0.27(0.05,0.54)$ \\
\hline $\mathbf{E R R}_{\mathrm{l}, \phi}$ & $0.05(-0.53,1.15)$ & $0.47(-0.32,2.12)$ & $0.27(-0.04,0.66)$ \\
\hline $\operatorname{Dmax}^{\mathrm{e}}$ & 0.32 & 0.01 & 0.35 \\
\hline $\mathbf{E R R}_{\mathrm{Dmax}, \phi}$ & I.3। (-0.7।, I.5। $)$ & $0.90(-0.17,2.96)$ & $1.59(0.03,2.54)$ \\
\hline Dev & 716.45 & 632.66 & 2120.13 \\
\hline Chi-sq & 3339.24 & 1047.11 & 2759.48 \\
\hline df & 2990 & $151 \mid$ & 2990 \\
\hline $\mathbf{R}^{f}$ & -14.36 & 425.41 & -19.98 \\
\hline Excess & 29.34 & 45.89 & 74.59 \\
\hline
\end{tabular}

${ }^{a} 0-20 \mathrm{mSv}$ subcohort, Excess Relative Risk ERR $=\beta \mathrm{D}_{\phi}+\sigma \mathrm{D}_{\phi} \mathrm{e}^{\left(-\tau \mathrm{D}_{\phi}\right)}$ with $\tau \geq 0$ and $\beta, \sigma, \tau$ constrained by I + ERR $\geq 0$ for all data cells; for $\mathrm{D}_{\phi}$ see Table I. The transient model is nested by $\beta=0$; the linear model is nested by $\sigma=0$ or by $\tau=0$; the control model is nested by $\beta=\sigma=0$. ${ }^{b}$ chosen in the range $5-44$ years. to minimise two-phase model Deviance; where italicised $\phi_{m}$ minimises Dev subject to ERR $R_{0.025, \phi} \geq 0$, a weaker condition than $\beta, \sigma \geq 0$.

c At $\phi_{m}, \beta, \sigma$ and $\tau$ are the fitted Maximum Likelihood Estimate parameter values.

${ }^{d}$ At $\phi_{m}$, the likelihood ratio tests $\mathrm{LRT}_{2 p \text {-trans }}$ and $\mathrm{LRT}_{2 \mathrm{p}-\text { lin }}$ compare the two-phase with the transient and linear models $\left(\chi^{2}\right.$ on I df); and LRT ${ }_{2 p-c o n}$ compares the two-phase model with the control model $\left(\chi^{2}\right.$ on $\left.2 \mathrm{df}\right)$

e At $\phi_{m}$, Dmax is the value of $D$ giving a local maximum of $E R R_{D, \phi}$

$f \mathbf{R}=1+\sigma / \beta$

Other definitions as in Table 2

subcohort for which the weighted adjusted colon dose does not fall in the interval $\left[\mathrm{x}_{\mathrm{i}-1}, \mathrm{x}_{\mathrm{i}}\right]$. The $\mathrm{x}_{\mathrm{i}}$ may be chosen so that the $S_{\mathrm{i}}$ have roughly equal p-y of observation. Then, fitting the two-phase and linear models for the liver $(\mathrm{M} / \mathrm{F})$ with $\phi=36.9$ to the reduced datasets $\mathrm{S}_{\mathrm{i}}$ gives $\mathrm{LRT}_{2 \mathrm{p} \text {-lin }}$ and $\mathrm{ERR}_{1}$ values as shown in Table 6. $\mathrm{LRT}_{2 \mathrm{p}-\text { lin }}$ values are $\geq$
$18.94(1 \mathrm{df})$ and $\mathrm{ERR}_{1}$ is fairly stable, varying from 1.21 to 1.74 .

The DS86 dosimetry used here and in LSS12 was re-investigated by a Joint Working Group using physical measurements, resulting in a new dosimetry system DS02 [11]. A 
Table 4: Category model ${ }^{a}$

\begin{tabular}{|c|c|c|c|}
\hline & Stomach & Liver & Lung \\
\hline gen & $M / F$ & $M / F$ & $M / F$ \\
\hline$\phi_{m}^{b}$ & 11.89 & 36.90 & 13.60 \\
\hline $\mathbf{D}_{\phi}>0$ & 1311 & 231 & 506 \\
\hline $\mathbf{T}_{1}{ }^{c}$ & 505007.81 & 104710.40 & 452429.89 \\
\hline $\mathbf{T}_{2}$ & $433 \mid 48.43$ & 100577.71 & 389939.77 \\
\hline $\mathbf{T}_{3}$ & 453123.28 & 97629.42 & $408 I \mid 4.01$ \\
\hline LRT $_{\text {cat-con }}{ }^{d}$ & 21.59 & 33.84 & 19.30 \\
\hline$\beta_{1} e^{e}$ & $0.48(0.2 \mathrm{I}, 0.8 \mathrm{I})$ & $1.30(0.68,2.15)$ & $0.96(0.17,2.46)$ \\
\hline$\beta_{2}$ & $0.16(-0.08,0.46)$ & $0.85(0.25,1.75)$ & $1.84(0.66,4.08)$ \\
\hline$\beta_{3}$ & $0.42(0.16,0.75)$ & $1.39(0.70,2.34)$ & $1.33(0.38,3.11)$ \\
\hline Dev & 1661.13 & 1235.38 & 1035.39 \\
\hline Chi-sq & 3391.69 & 2451.56 & 3111.30 \\
\hline \multirow[t]{2}{*}{ df } & 2990 & 2990 & 2990 \\
\hline & Colon & Uterus & All solid \\
\hline gen & $M / F$ & $\mathrm{~F}$ & $M / F$ \\
\hline$\phi_{\mathrm{m}}^{b}$ & 20.28 & 26.91 & 43.86 \\
\hline $\mathbf{D}_{\phi}>0$ & 184 & 127 & 365 \\
\hline $\mathbf{T}_{1}^{c}$ & 342887.98 & 128431.04 & 24656.43 \\
\hline $\mathbf{T}_{2}$ & 288767.71 & 153667.68 & 21860.18 \\
\hline $\mathbf{T}_{3}$ & 307331.28 & 145793.72 & 21917.87 \\
\hline $\mathbf{L R T}_{\text {cat-con }}{ }^{\mathrm{d}}$ & 1.57 & 8.08 & 16.31 \\
\hline$\beta_{1^{e}}$ & $0.07(-0.40,0.95)$ & $0.92(0.19,2.08)$ & $0.13(-0.06,0.34)$ \\
\hline$\beta_{2}$ & $0.32(-0.31,1.52)$ & $0.28(-0.30,1.29)$ & $0.43(0.16,0.74)$ \\
\hline$\beta_{3}$ & $0.02(-0.44,0.89)$ & $0.52(-0.08,1.48)$ & $0.29(0.06,0.56)$ \\
\hline Dev & 718.42 & 630.89 & 2121.74 \\
\hline Chi-sq & 3625.26 & 1038.26 & 2772.40 \\
\hline df & 2990 & 15|| & 2990 \\
\hline
\end{tabular}

${ }^{a} 0-20 \mathrm{mSv}$ subcohort, Excess Relative Risk ERR $=\beta_{1}$ dosecat $_{1}+\beta_{2}$ dosecat $_{2}+\beta_{3}$ dosecat $_{3}$ with $\beta_{\mathrm{i}}{\text { constrained by } \mathrm{I}+\beta_{\mathrm{i}} \geq 0 \text {; dosecat }}_{1}=\mathrm{I}$ if $0<\mathrm{D}_{\phi} \leq$ 0.025 , and $=0$ otherwise; dosecat ${ }_{2}=I$ if $0.025<D_{\phi} \leq 0.05$, and $=0$ otherwise; dosecat ${ }_{3}=I$ if $0.05<D_{\phi}$, and $=0$ otherwise. The Control model is nested by $\beta_{1}=\beta_{2}=\beta_{3}=0$.

$b$ Latency $\phi_{m}$ is chosen from the results of the two-phase model (Table 3)

${ }^{c}$ At $\phi_{m}$, $T_{j}$ is the $p-y$ observation for which dosecat ${ }_{i}=1, j=1,2,3$

${ }^{d}$ At $\phi_{m}$, the likelihood ratio test $L R T_{\text {cat-con }}$ compares the category model with the control model ( $\chi^{2}$ on $\left.3 \mathrm{df}\right)$

e At $\phi_{m}, \beta_{i}$ are the fitted Maximum Likelihood Estimate parameter values, with $95 \% \mathrm{Cl}$ 's

Other definitions as in Table 3.

dataset using DS02 and enabling comparison with DS86 was released by RERF last year and can be downloaded as DS02can.dat from the RERF website [9]. However, the cancer mortality fields in this dataset only show deaths from solid cancers (combined), liquid cancers, and leukaemia. Investigation of the stomach, liver, and lung as individual sites is not possible from this public dataset. Furthermore, the stratification of the new dataset differs from that in LSS12 and it is not possible to simply read off the DS02 values for cells in the LSS12 data.

Nonetheless for those cells in the DS02 dataset which have a DS86 dose, the weighted adjusted DS02 colon dose using neutron $\mathrm{RBE}=10$, shown as "cola02w10", can be compared with the corresponding DS86 dose variable shown as "cola86w10".

Only 11 cells, with 13.83 p-y and no solid cancer deaths, have cola02w10 $<0.005 \mathrm{~Sv}$ and cola86w10 $\geq 0.005 \mathrm{~Sv}$. Only 5 cells, with 11.24 p-y and no solid cancer deaths, have cola02w10 $\geq 0.005 \mathrm{~Sv}$ and cola86w10 $<0.005 \mathrm{~Sv}$. For cells with cola86w10 $\geq 0.005 \mathrm{~Sv}$ the ratio $\theta=$ cola02w10/cola86w10 varies from 0.216 to 1.925 with mean 1.08 and standard deviation 0.082 . There are only 7 cells, with $10.47 \mathrm{p}-\mathrm{y}$ and no solid cancer deaths, for which $\theta<0.5$. Likewise 92 cells, with 195.84 p-y and 3 solid cancer deaths, have $\theta>1.5$. In the subcohort with $0.005 \mathrm{~Sv} \leq$ cola86w10 $\leq 0.02 \mathrm{~Sv}, \theta$ varies from 0.216 to 1.27 with 


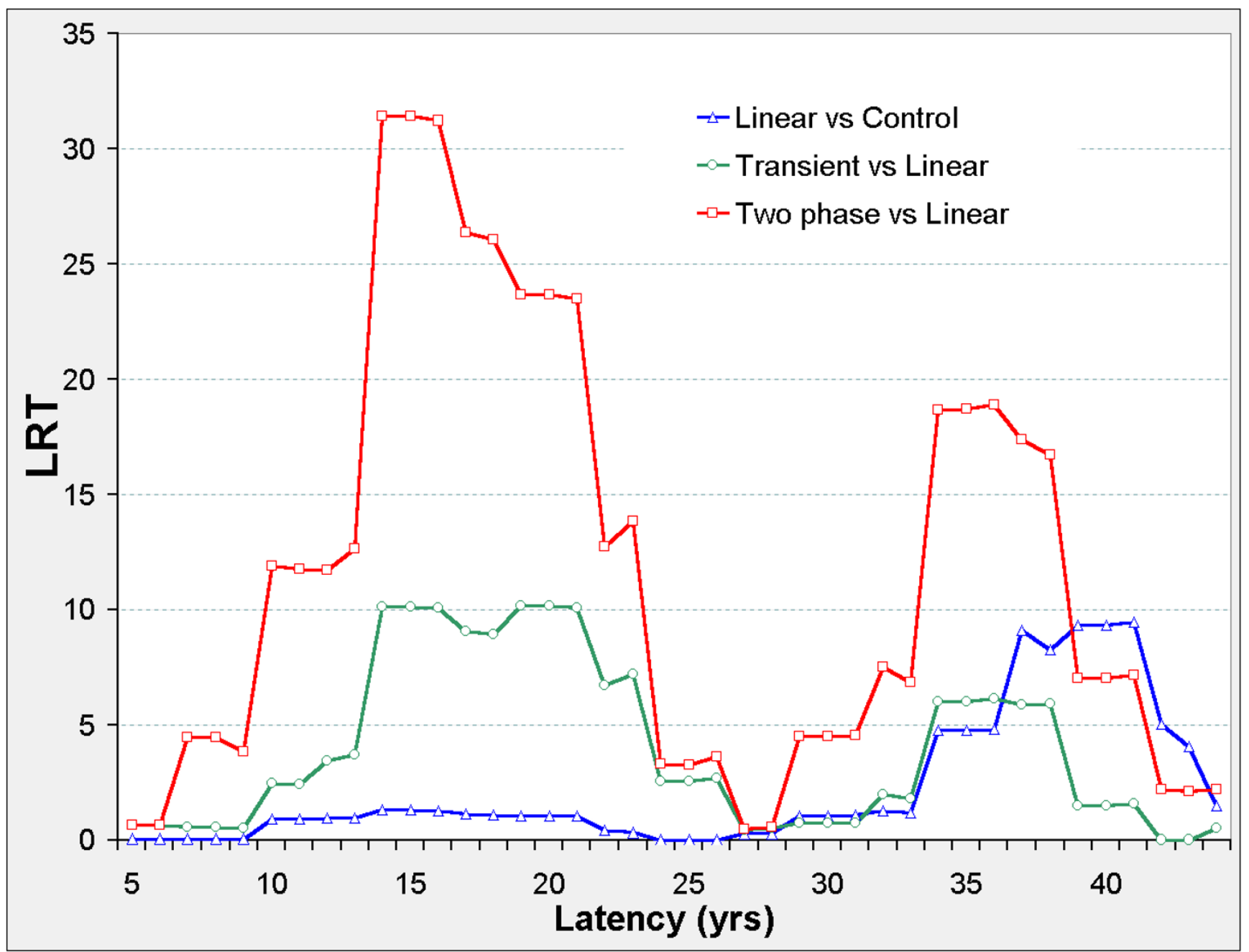

Figure 4

Liver cancer mortality in 0 - 20 mSv subcohort, LRT vs latency. Axes and model definitions as in Figure 2.

mean 1.026 and standard deviation 0.077 . There are 15 cells with 78.5 p-y and 2 solid cancer deaths, for which $\theta$ $<0.8$, and 9 cells with 9.88 p-y and 1 solid cancer death, for which $\theta>1.2$

Thus if DS02 is an accurate estimate of the flash dose, there is virtually no misclassification of DS86 between the categories "above $5 \mathrm{mSv}$ " and "below $5 \mathrm{mSv}$ ", and above $5 \mathrm{mSv}$ the DS86 dose is a reasonable estimate, though $8 \%$ below DS02 on average.

The scope in this paper for misclassification of the dose is therefore reduced if doses below $5 \mathrm{mSv}$ are taken as baseline and doses from 5 to $20 \mathrm{mSv}$ are taken as a single category which is then analysed with latency. While that approach is too crude to detect non-linearity, it gives very similar results for the liver to those found with the linear model.
As shown in Table 1 the optimal latency for the liver (M/ F) using the linear model is $\phi=38.58$, for which comparison with the control model has $\mathrm{LRT}_{\text {lin-con }}=11.21, \beta=$ $\mathrm{ERR}_{1}=0.69(0.25,1.26)$. Now define $\mathrm{E}=1$ if Time-SinceExposure $\geq 38.58$ and $5 \mathrm{mSv} \leq$ colon dose $\leq 20 \mathrm{mSv}, \mathrm{E}=0$ otherwise. As Time-Since-Exposure is known, errors in $\mathrm{E}$ can only arise if doses below $5 \mathrm{mSv}$ were misclasssified as above $5 \mathrm{mSv}$, or vice versa. Fitting the model defined by $\mathrm{ERR}=\gamma \mathrm{E}$ to the liver $(\mathrm{M} / \mathrm{F})$ data for the $0-20 \mathrm{mSv}$ dose range and comparing with the control model $(\gamma=0)$ gives LRT $=11.04, \gamma=0.67(0.24,1.21)$. Thus the results for the linear model can be reproduced with a two-category model using a cutpoint of $5 \mathrm{mSv}$, and these categories are almost identical whether defined by DS86 or DS02.

As a further test, the liver data were modelled in the extended DS86 dose range $5 \mathrm{mSv}-500 \mathrm{mSv}$, where DS86 and DS02 are in reasonable agreement. The two-phase 


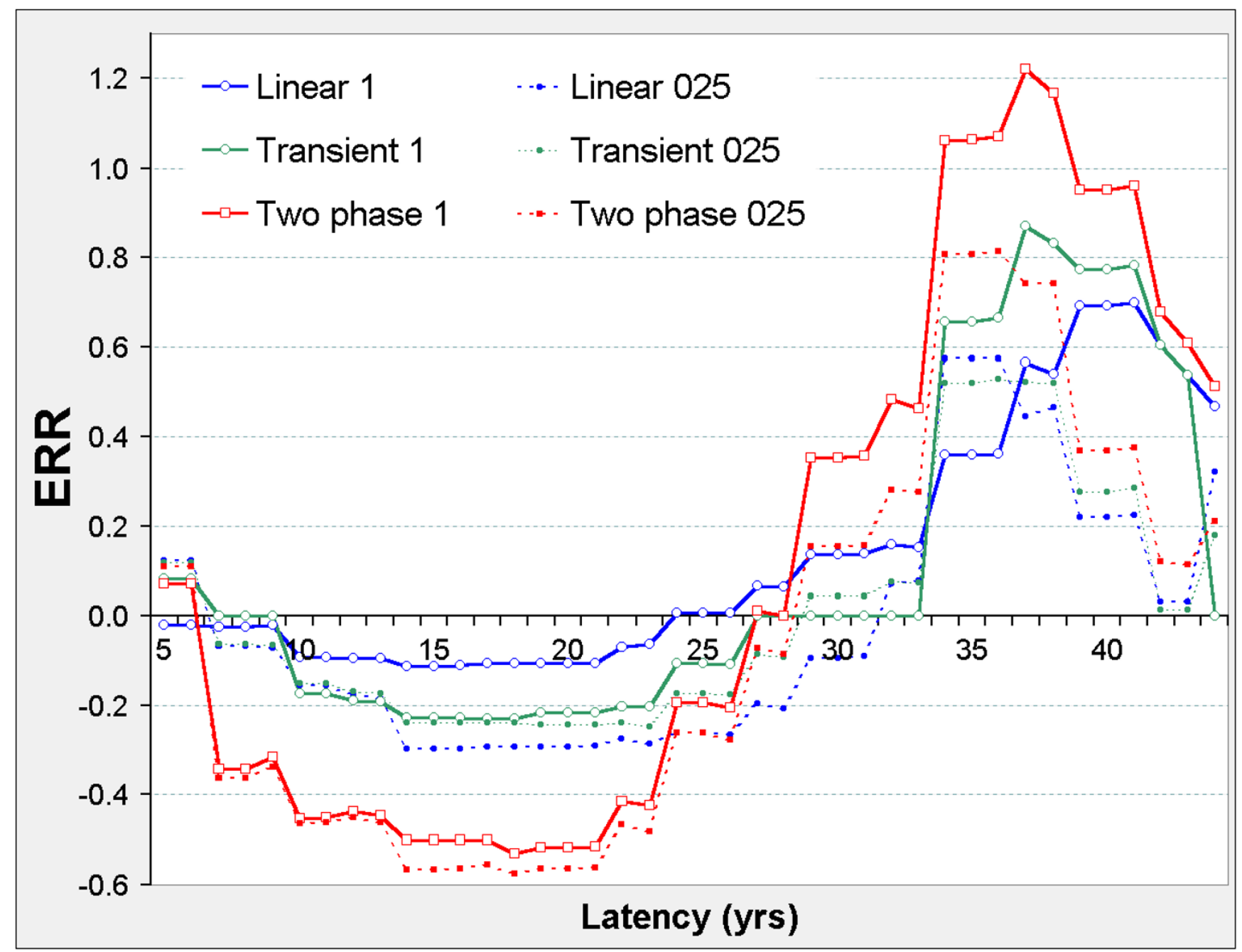

Figure 5

Liver cancer mortality in $\mathbf{0}-20$ mSv subcohort, ERR vs latency. Axes and model definitions as in Figure 3.

model is a significant improvement on the linear model at latency $\phi=36.9$ years, with $\mathrm{LRT}_{2 \mathrm{p}-\mathrm{lin}}=10.37(1 \mathrm{df})$ and $\mathrm{ERR}_{1}=0.74(0.10,1.79)$.

Similar results for the liver are obtained from the $0-500$ $\mathrm{mSv}$ dose range. The two-phase model is a significant improvement on the linear model at latency $\phi=36.9$ years, with $\mathrm{LRT}_{2 \mathrm{p}-\mathrm{lin}}=16.86(1 \mathrm{df})$ and $\mathrm{ERR}_{1}=0.76(0.15$, 1.66).

For comparison, the results for the liver obtained from the $0-20 \mathrm{mSv}$ dose range at latency $\phi=36.9$ years, are $\mathrm{LRT}_{2 \mathrm{p}}$ $\operatorname{lin}=29.67(1 \mathrm{df})$ and $\mathrm{ERR}_{1}=1.46(0.50,3.00)$. Similar results when "city" is omitted from the model are shown in Table 3.

The DS02 public dataset does not show the liver but does allow modelling of all-solid cancers. The subcohort $S$ defined by cola02w $10 \leq 0.02$ and Time-Since-Exposure $\leq$ 45.39 years (the maximum value in the $0-20 \mathrm{mSv}$ subcohort of LSS12 data) has 1682335.39 p-y and 4363 cases, roughly comparable to the LSS12 subcohort analysed with DS86 in this paper. Models were defined as previously, but using cola02w10 in place of the DS86 weighted adjusted colon dose. None of the cells in S contain Nagasaki factory workers. Controls for "city" and "ground distance category" (proximal or distal) were introduced, 


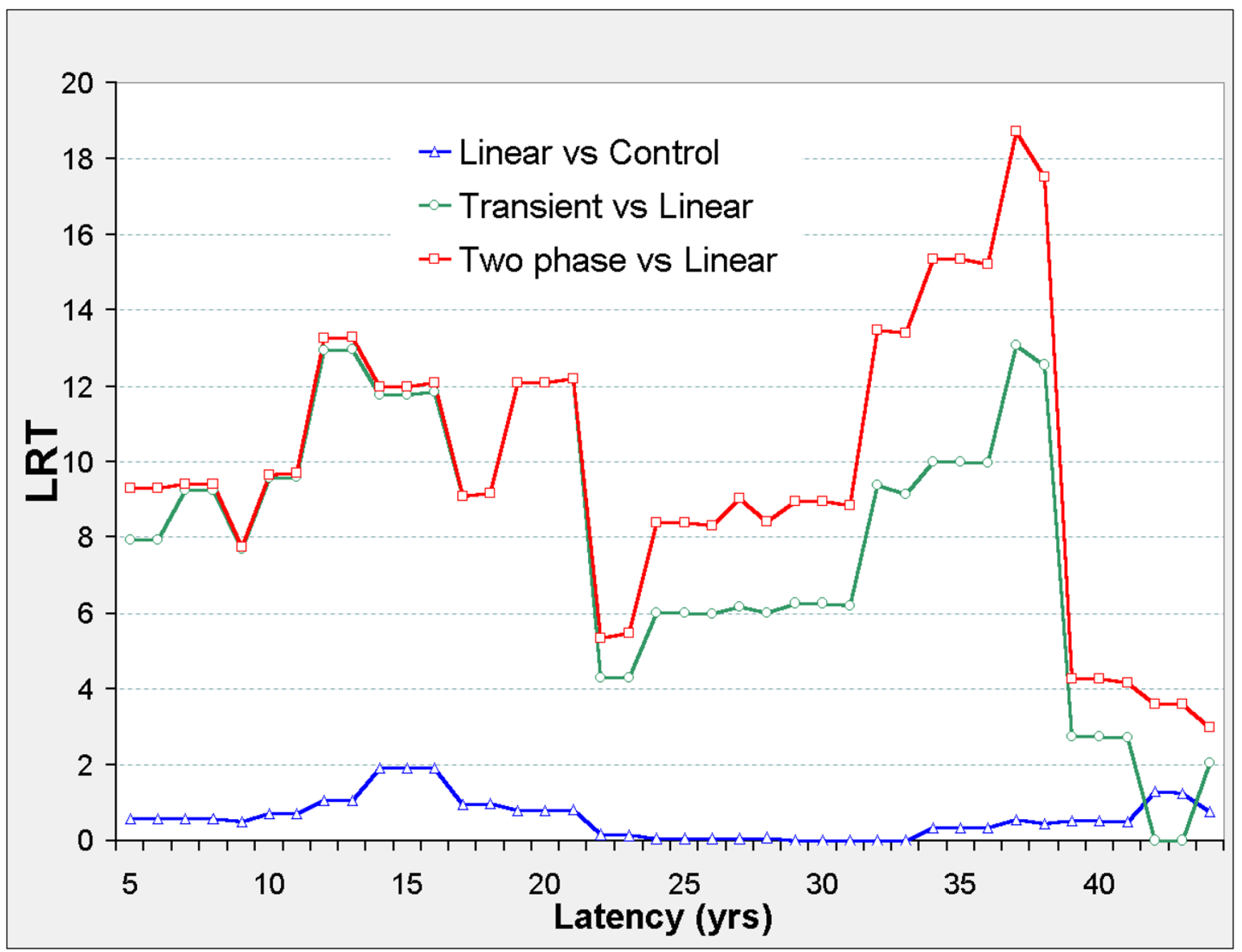

Figure 6

Lung cancer mortality in 0 - 20 mSv subcohort, LRT vs latency. Axes and model definitions as in Figure 2.

though they had little impact. If the linear model is fitted to $S$ with latency $\phi=43.29$ years then LRT $_{\text {lin-con }}=3.79(1$ df). For the two-phase model LRT $_{2 \mathrm{p} \text {-con }}=10.49(2 \mathrm{df})$ and $\mathrm{LRT}_{2 \mathrm{p} \text {-lin }}=6.70(1 \mathrm{df})$, again showing non-linearity. $\mathrm{ERR}_{1}$ $=0.223(-0.07,0.58)$. For the DS86 results, Table 3 shows $\mathrm{ERR}_{1}=0.272(-0.04,0.66)$ at latency 43.86 years.

The estimates of $\mathrm{ERR}_{1}$ for all-solid cancers are similar whether derived from the $0-20 \mathrm{mSv}$ subcohort of LSS12, or the comparable $0-20 \mathrm{mSv}$ subcohort of the DS02 data.

The DS02 data contains an additional 10 years of followup. Non-linearity is still present in the extended cohort. Define the subcohort $\mathrm{T}$ by cola02w10 $\leq 0.02$ without restricting Time-Since-Exposure. At latency 43.29 years the linear model is indistinguishable from the control model $(\mathrm{LRT}=0.47)$ but the two-phase model has $\mathrm{LRT}_{2 \mathrm{p}}$ con $=9.49(2 \mathrm{df})$ and $\mathrm{LRT}_{2 \mathrm{p}-\mathrm{lin}}=9.02(1 \mathrm{df}) . \mathrm{ERR}_{1}=0.08(-$ $0.07,0.26)$.

\section{Discussion}

This paper begins from the publicly available data, and I do not know if a comparable analysis of the anonymous individual data would show similar results.

In re-analysing portions of the 1950-90 grouped data, the approach here has four features.

1) To predict risks at $10 \mathrm{mSv}$, the $0-20 \mathrm{mSv}$ data is analysed directly.

2) A variable lag period is used to analyse latency.

3) Dosimetry data is not reduced to categories before modelling. Dose is taken as a numerical variable, defined 


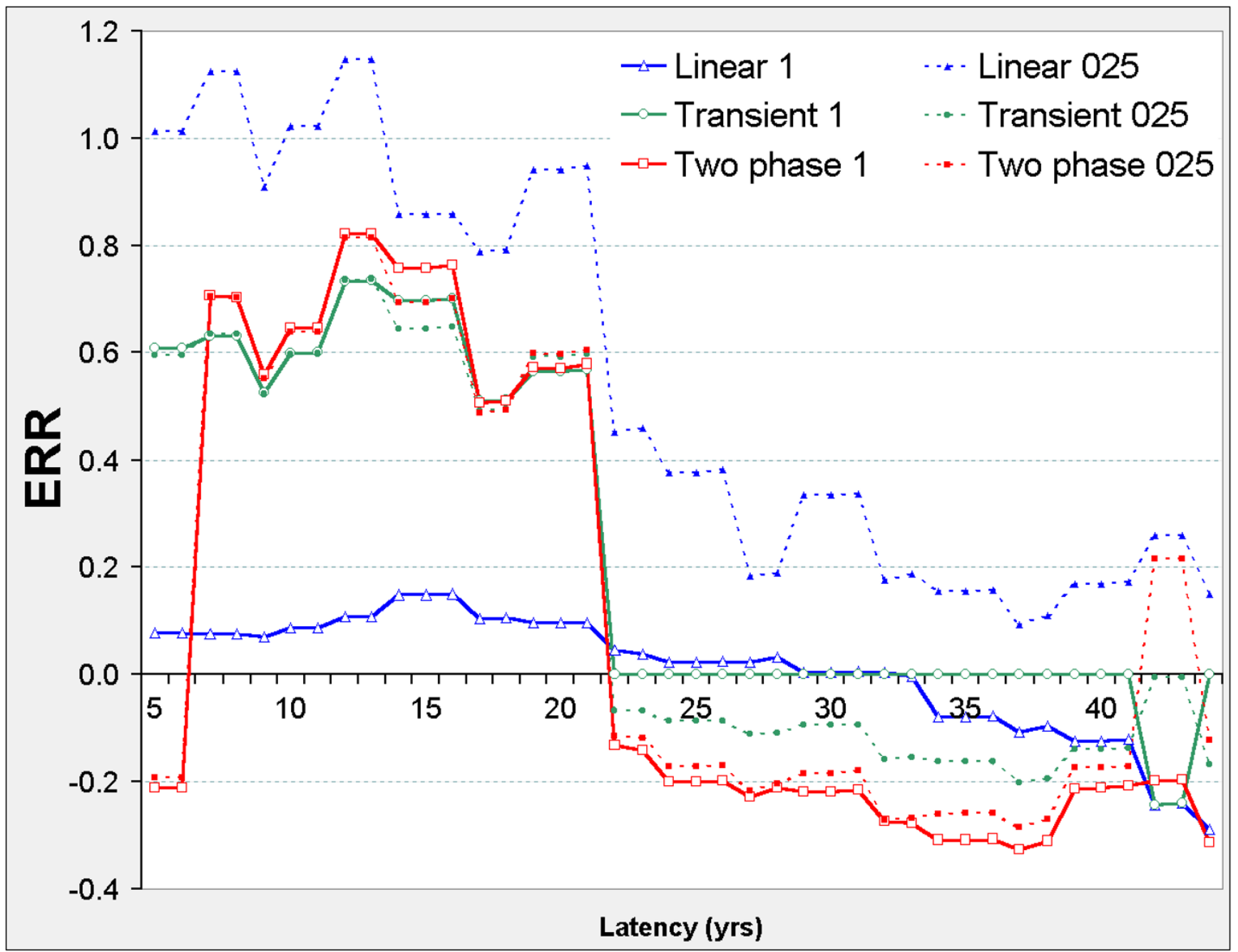

Figure 7

Lung cancer mortality in 0 - 20 mSv subcohort, ERR vs latency. Axes and model definitions as in Figure 3.

on the grouped data cells, but results are also tested in a 4category model with baseline defined by $\mathrm{D}_{\phi}=0$ and cutpoints which roughly equipartition the $\mathrm{p}-\mathrm{y}$ in non-baseline categories.

4) Linearity of the dose response is tested by nesting within more complex models.

With a fixed 5 year lag, none of the cancers considered here show significant effects in the $0-20 \mathrm{mSv}$ dose range using a linear model. Allowing latency to vary in this model gives significant positive responses for the liver and all-solid cancers.

Latency reflects biochemical changes required after initial radiation if mutant cells are to progress and form a tumour eventually identified as cause of death, and historical changes in environmental factors which interact with radiation for a particular cancer. Thus latency may be organ and gender specific.

Rothman [13] illustrates how ignoring latency may mask important effects, whether or not the original exposure was brief. Analysis using the lagged dose $D_{\phi}$ is a simple approach depending on only one parameter. The response might be clearer by modelling the effect of $\mathrm{D}^{*} \mathrm{w}$, with $\mathrm{w}$ some more general function of Time-Since-Exposure. Such models have been applied to lung cancer mortality in uranium miner cohorts $[14,15]$.

If the linear model were appropriate throughout the low dose region, we might expect $\operatorname{ERR}_{0.025, \phi} \sim 0.025\left(\mathrm{ERR}_{1, \phi}\right)$ 


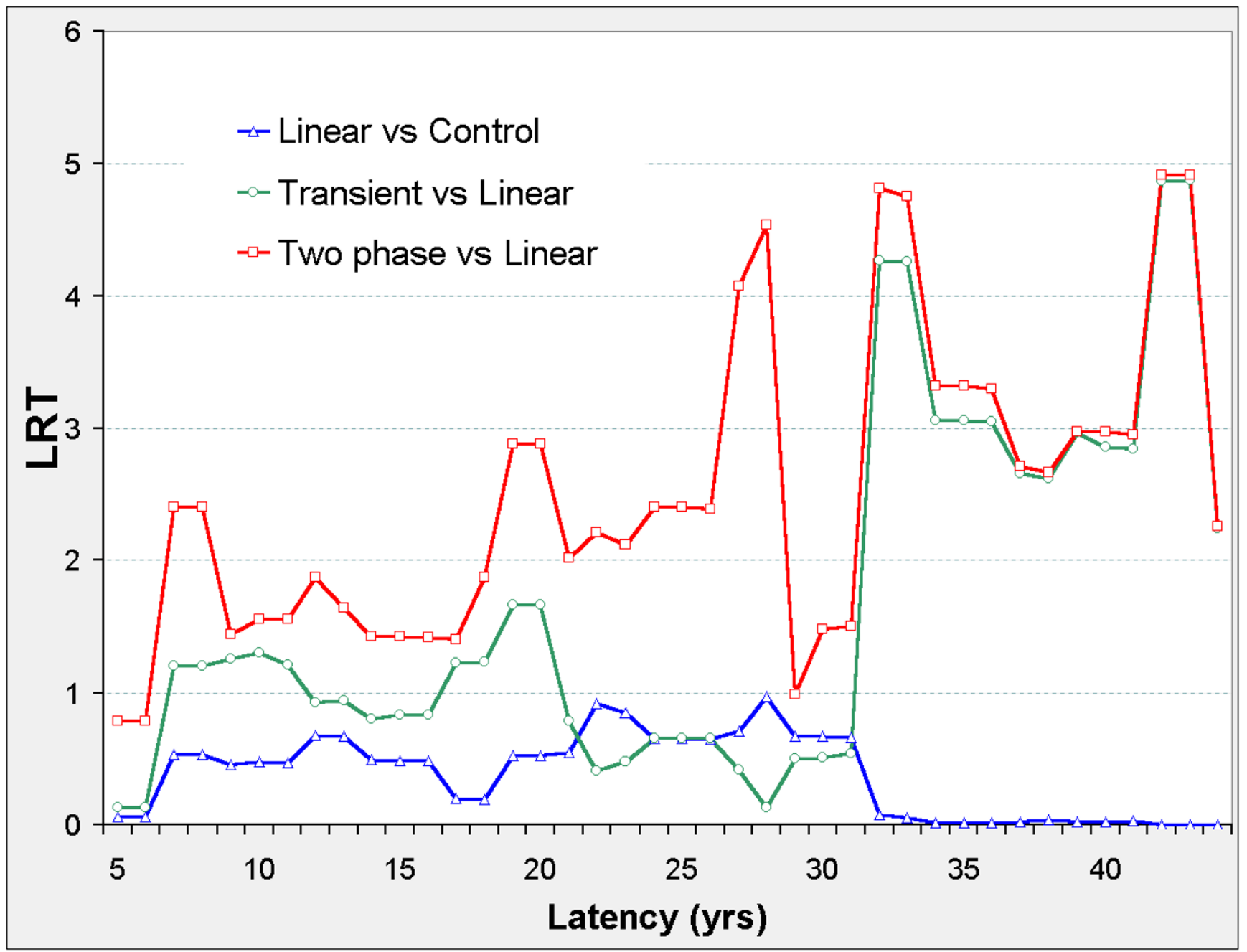

Figure 8

Colon cancer mortality in 0 - 20 mSv subcohort, LRT vs latency. Axes and model definitions as in Figure 2.

whatever data were used to estimate each ERR. In fact, the ERR values are often comparable. Two non-linear models give significant improvements in the $0-20 \mathrm{mSv}$ dose range for the stomach, liver, lung, uterus and all-solid cancers, and for various gender specific sites. These improvements are strong, for example $\mathrm{p}<0.001$ when comparing the two-phase and linear models $(\mathrm{M} / \mathrm{F})$ for stomach, liver, lung, and all-solid; and $\mathrm{p}<0.000001$ for the liver.

Unlike the linear and control models, the transient and two-phase models require extensive computation as the Deviance may have multiple local minima at any choice of latency $\phi$ (fixed when fitting the model). Computation involves a search for local minima, selection of the minimum Deviance at $\phi$, and then a comparison amongst these minima for different $\phi$ values. The optimal $\phi$ is chosen to give the absolute minimum Deviance, with or without the constraint that $\mathrm{ERR}_{0.025}$ be non-negative. The search is streamlined by restricting $\phi$ to $5,6, \ldots 44$ and later refined to consider all $\phi$ (to 2 decimal places) in a range which appears likely to contain the optimal value.

I do not know of any general analytical method which might limit the total number of local minima at fixed $\phi$ in this data. Instead, the $\tau$ axis is partitioned (see Methods). Fitting the model with $\tau$ constrained to an interval typically yields a $\tau$ value at either endpoint, reflecting the constraint, except for those intervals which contain $\tau$ values at which the Deviance attains a local minimum.

Searches begin from the control parameter values which optimise the control model, while $\tau$ is confined to the relevant interval and $\beta, \sigma$ are initially set to 0 . Conceivably, this choice of initial conditions may cause the NewtonRaphson iteration to miss some local minima, though testing other initial conditions did not detect any other 


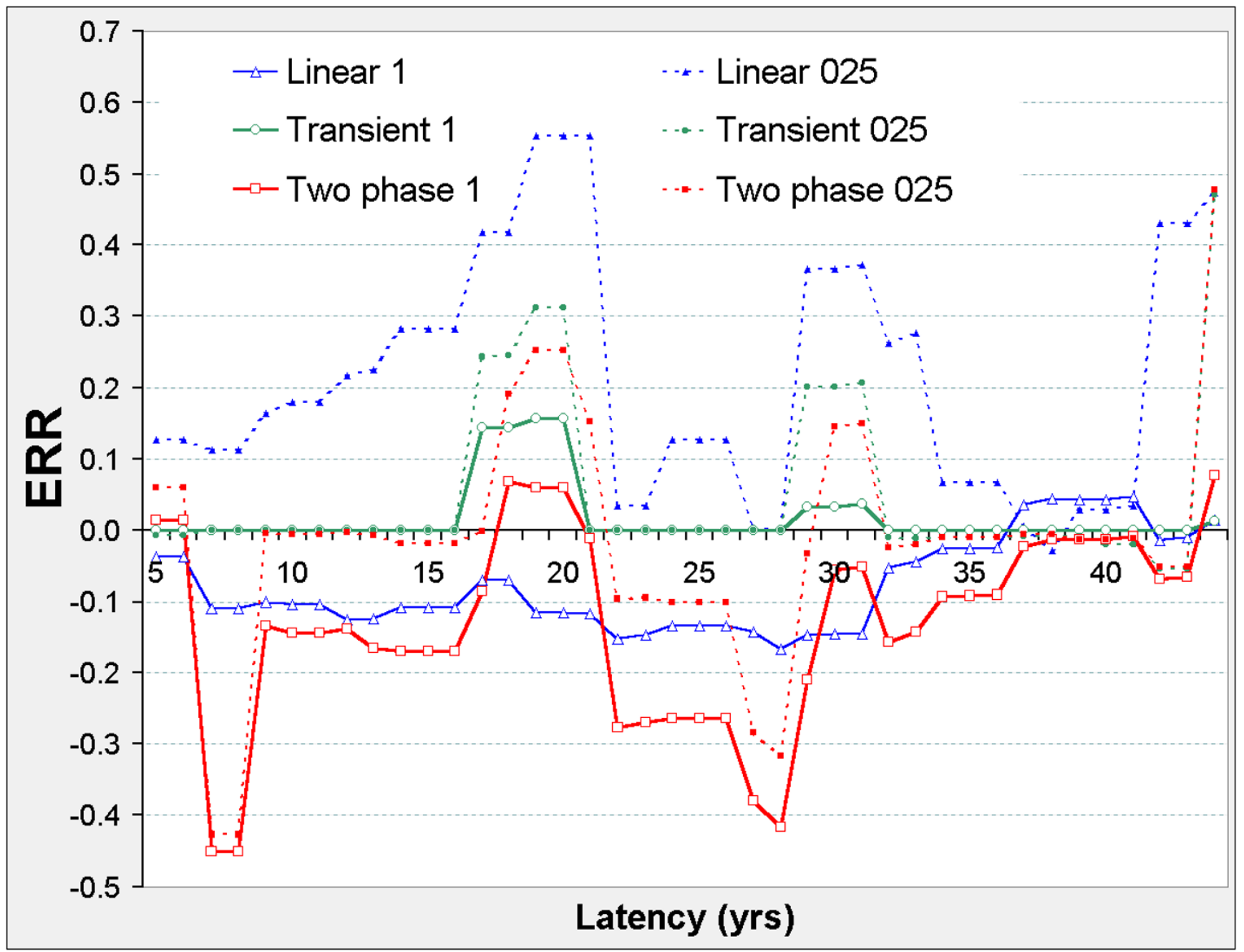

Figure 9

Colon cancer mortality in 0 - 20 mSv subcohort, ERR vs latency. Axes and model definitions as in Figure 3.

solutions. In any case the minimum Deviance at any particular $\phi$ can be no higher than the values found here, so any missing minima could only strengthen the evidence of non-linearity.

Fitting the two-phase model to the lung data illustrates these issues. When $\phi=13$ three local minima are detected. At $\tau=4.51$, Dev $=1040.35$. At $\tau=13.86$, Dev $=1040.87$. At $\tau=175.63$, Dev $=1050.25$. The minimum Dev at $\phi=$ 13 is thus 1040.35. The linear model has Dev $=1053.64$. Thus $\mathrm{LRT}_{2 \mathrm{p} \text {-lin }}$ for comparing the two-phase and linear models is $1053.64-1040.35=13.29$, and it is this value which is displayed in Figure 6 when $\phi=13$. Likewise the ERR value computed at this minimum Dev is displayed in Figure 7 when $\phi=13$. The resulting graphs indicate the region to be searched for an optimal choice of $\phi$, subject to the constraint ERR $\geq 0$. This optimum is $\phi=13.6$, the value shown in Table 3. At this latency there are again 3 local minima, two of which have similar Dev. At $\phi=13.6$ the minimum at $\tau=4.45$ with $\mathrm{Dev}=1038.58$ has $\mathrm{ERR}_{1}=$ 0.88 while the local minimum at $\tau=13.54$ with $\mathrm{Dev}=$ 1039.26 has $\mathrm{ERR}_{1}=1.10$. Note that while $\tau$ varies widely without appreciable change in $\mathrm{Dev}, \mathrm{ERR}_{1}$ is much more stable. In this example, the $95 \% \mathrm{CI}$ is $(0.12,3.36)$. For this reason, ERR is a much better focus for analysis than the model parameters themselves.

Confidence intervals for ERR are often somewhat wider in the two-phase model than in the simpler transient model which is sufficient to describe the lung and all-solid (M/F, F) data. However, as well as improving the fit for the stomach, liver and all-solid (M) the two-phase model gives a more coherent account of the latency regions of significant positive or negative dose response. 


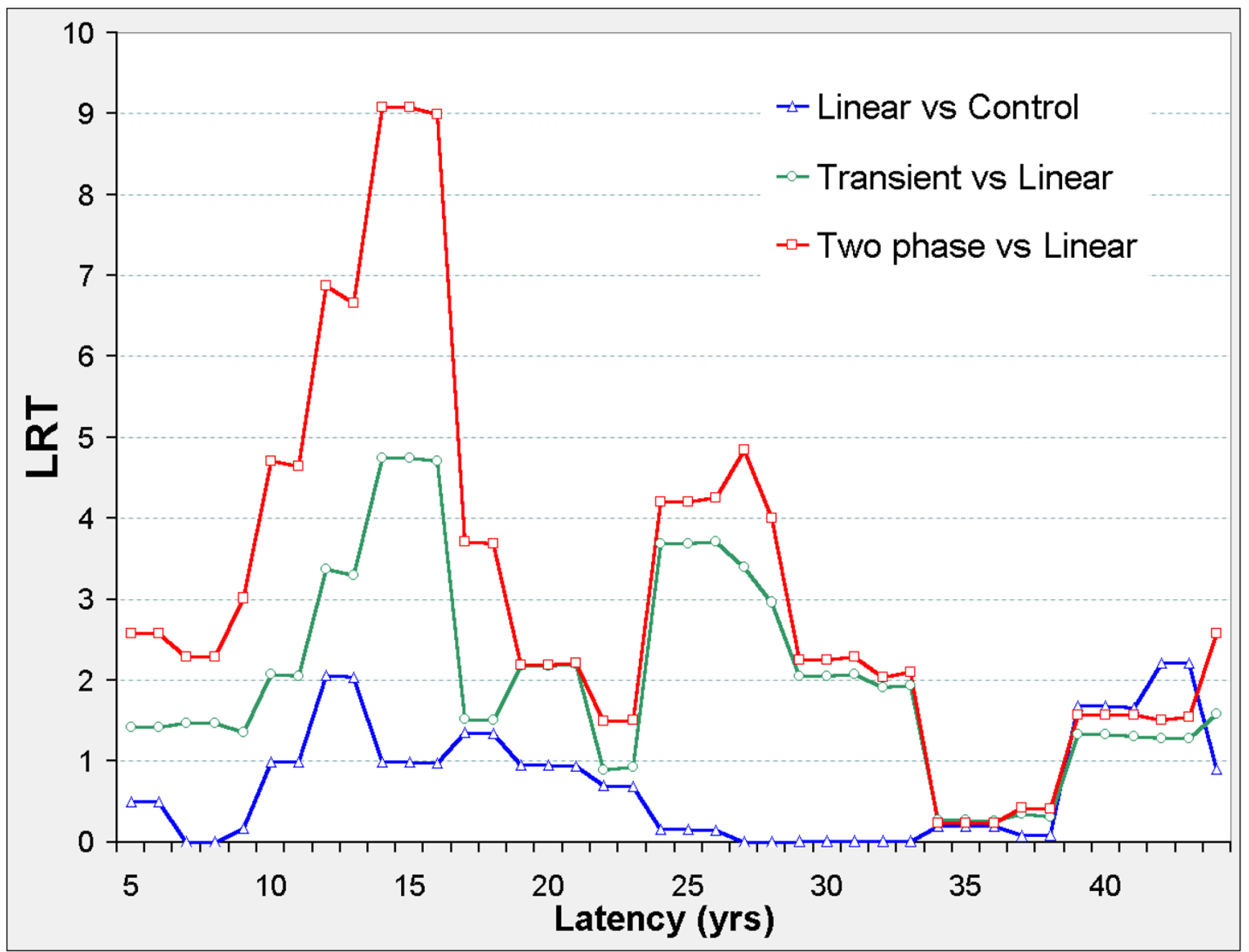

Figure 10

Uterine cancer mortality in 0 - 20 mSv subcohort, LRT vs latency. Axes and model definitions as in Figure 2.

Linear extrapolation of the LSS12 results shows almost no response at the doses considered here. Whilst LSS12 uses organ doses and a different system of controls, these factors do not account for the large discrepancy in risk estimates. Alternative controls affect the estimates by a factor of 2 or less, and the use of organ doses has even less impact. Significant discrepancies arise when the dose range is restricted to $0-20 \mathrm{mSv}$ and latency is included in the analysis.

Stewart and Kneale [16] found evidence of selection bias in the LSS 1950 - 1985 cohort, thought to reflect the fact that only those victims able to survive from 1945 - 1950 were eligible to enter the cohort. The test group used by Stewart and Kneale to detect bias included less than $4 \%$ of the total cohort but had nearly $30 \%$ of high doses (> 1000 $\mathrm{mSv})$. It is plausible that such bias would be reduced in the $0-20 \mathrm{mSv}$ subcohort, but I cannot test this from the publicly available RERF data.

Pierce and Preston [17] analysed all-solid cancer incidence in Japanese survivors from the 1958 - 1994 tumour registry data for the range 0 - $500 \mathrm{mSv}$, using a linear ERR model based on colon dose and a categorical model with cutpoints 0, 5, 20, 100, 200, 250, 300, $400 \mathrm{mSv}$ (colon dose). Estimates correspond to ERR 0.006 at $10 \mathrm{mSv}$. Likewise, if the linear model here is applied to all-solid cancer mortality (1950-90) in the $0-500 \mathrm{mSv}$ dose range with latency 5 years, $\mathrm{ERR}_{1}=0.004$ with $\mathrm{LRT}=8.58$.

Pierce and Preston focus on survivors who were exposed relatively near the hypocentres of the A-bombs and exclude distal survivors ( $\geq 3 \mathrm{~km}$ distant) on the grounds that they had higher baseline cancer rates and that some lifestyle cancer risk factors correlate with urban-rural dis- 


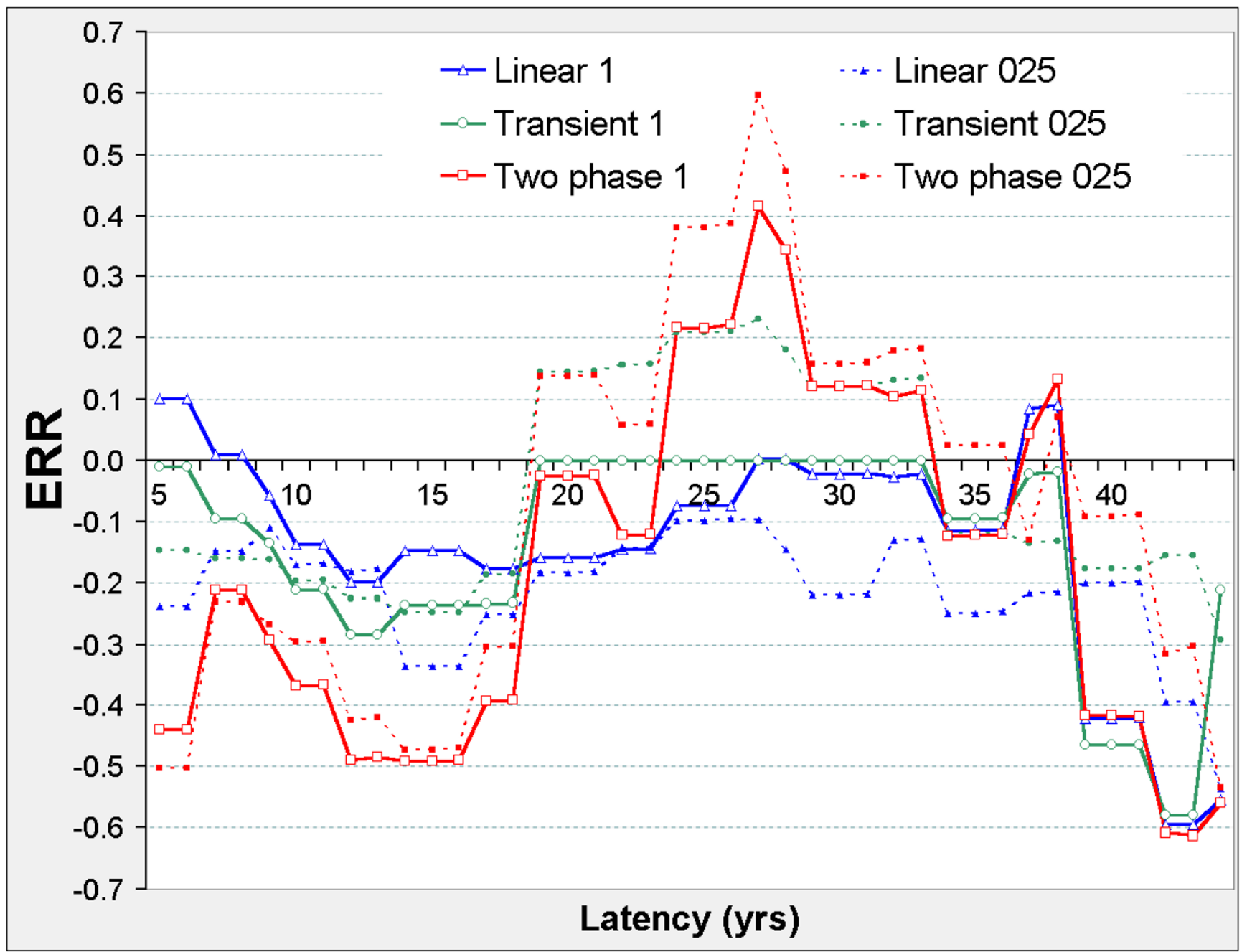

Figure I I

Uterine cancer mortality in 0 - 20 mSv subcohort, ERR vs latency. Axes and model definitions as in Figure 3.

tinctions, though cigarette smoking had almost no correlation with estimated dose or distance from the hypocentre. Excluding the distal group lowered the baseline by about $5 \%$ in their data. Although that is significant in relation to the estimates of ERR in the RERF studies, it is marginal compared to the ERR values found here with the latency models.

The 0 - 20 mSv subcohort contains many proximal as well as distal survivors $(10,159$ proximal survivors in the incidence dataset had doses below $5 \mathrm{mSv}$ ). The results here may of course reflect other risk factors which may correlate and/or interact with radiation dose, but which could only be approached through the individual data. Investigation of possible confounders should also consider latency and non-linear models such as those analysed here, given their clear superiority to the linear model with fixed 5 year lag, for the low-dose grouped data.
This paper is based on the DS86 dosimetry and the results could reflect dosimetry errors, arising from incorrect estimation of the flash dose or by omitting other radiation sources. The doses received in Hiroshima and Nagasaki include the flash dose (used here), induced radioactivity in building materials or soil which persisted for several weeks, "black rain" which fell in the immediate aftermath of the bombings, natural background radiation, global fallout from atmospheric weapons tests, occupational and medical exposures. The public data does not include any individual occupational or medical exposures. Natural background and global fallout should not be correlated with the exposures arising directly from the bombs in 1945, and would be expected to bias results towards the null. Doses from induced radioactivity and "black rain" could be relevant, but currently available RERF public datasets do not include either of these two additional sources. 


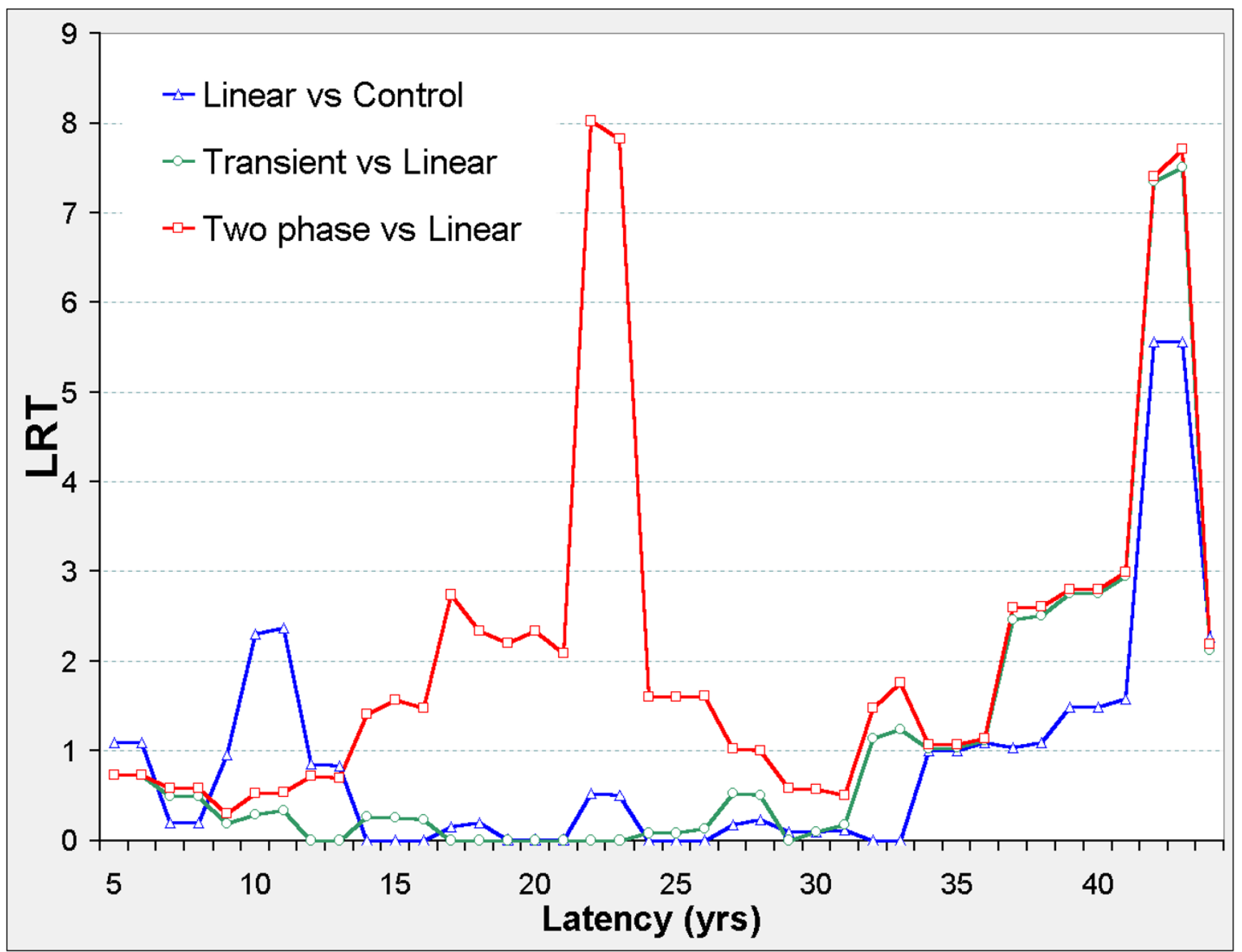

Figure 12

All-solid cancer mortality in 0 - 20 mSv subcohort, LRT vs latency. Axes and model definitions as in Figure 2.

Errors in the flash dose itself are unlikely to explain the results. Non-linearity and large values of ERR at $10 \mathrm{mSv}$ persist when the zero-dose data is deleted from the $0-20$ $\mathrm{mSv}$ subcohort and likewise when ten intervals spanning $0-20 \mathrm{mSv}$ are used to delete dose ranges from the data.

The DS02 dataset shows that there is virtually no misclassification between the DS86 categories "below $5 \mathrm{mSv}$ " and "above $5 \mathrm{mSv}$ ". For the liver at latency 36.9 years, it makes little difference whether dose is taken as a categorical variable defined by the $5 \mathrm{mSv}$ cutpoint in the data stratification, or as a numerical value analysed with the linear model.

DS02 and DS86 are in reasonable agreement above 5 mSv. If datacells with DS86 dose below $5 \mathrm{mSv}$ are excluded from the $0-20 \mathrm{mSv}$ dose range, the two-phase model is no longer a significant improvement on the linear model for the liver. However, very similar evidence of non-linearity for the liver arises in the $5 \mathrm{mSv}-500 \mathrm{mSv}$ dose range where DS86 is a reasonable approximation to DS02, and in the $0-500 \mathrm{mSv}$ dose range considered by Pierce and Preston [17].

Analysis of solid cancers using DS02 in the $0-20 \mathrm{mSv}$ dose range gives estimates of ERR comparable to those derived from DS86.

These various arguments suggest that the results are unlikely to be explained by errors in dosimetry of the flash dose, although DS02 like DS86 is subject to some uncertainty due to random errors in specifying individual loca- 


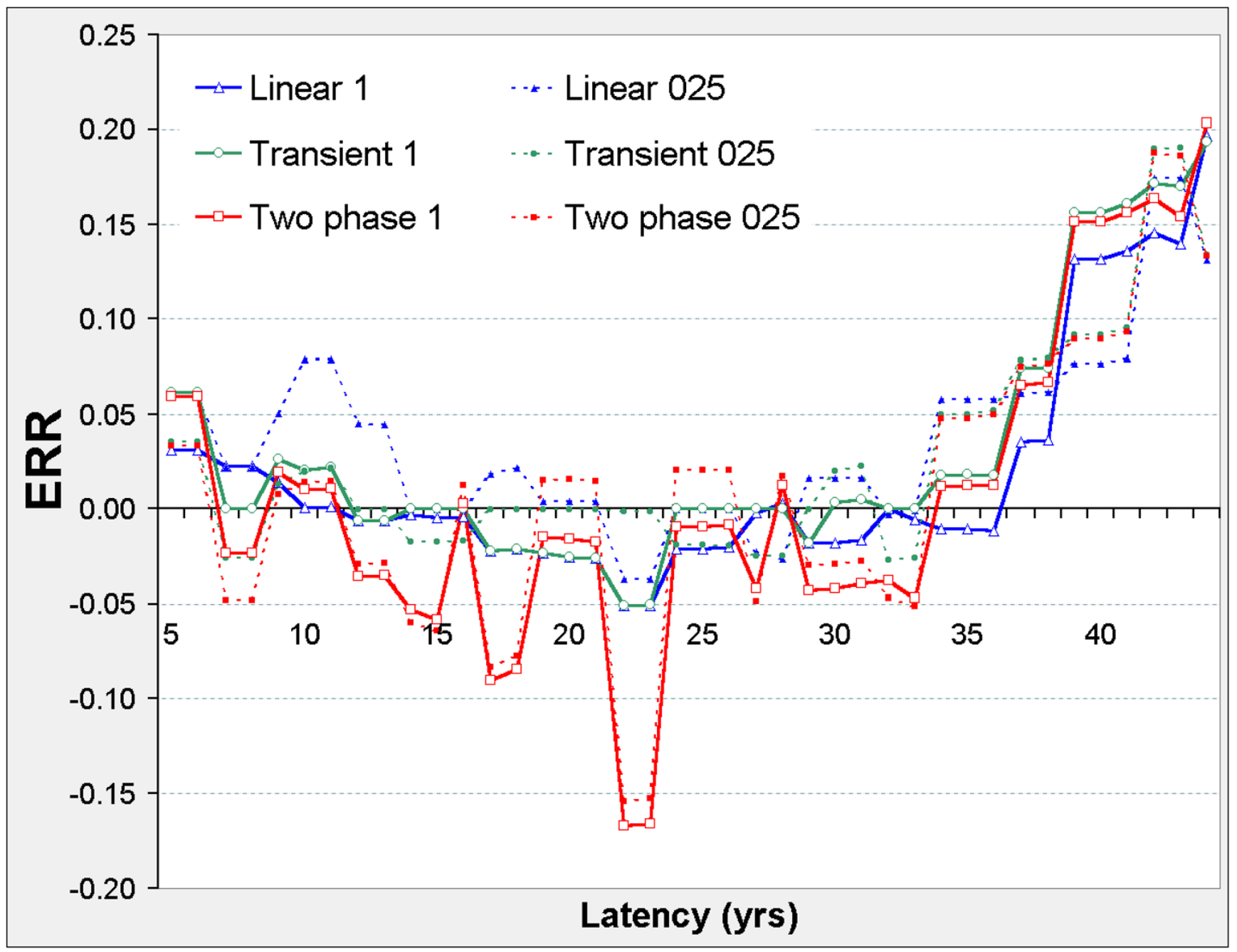

Figure 13

All-solid cancer mortality in 0 - 20 mSv subcohort, ERR vs latency. Axes and model definitions as in Figure 3.

tion and shielding. Separately, induced radioactivity and "black rain" represent additional doses not reported by DS86 or DS02.

Induced radioactivity appears unlikely to fully explain the results. According to the RERF website [6] "The closer to the hypocentre, the higher was the dose [from induced radioactivity]. Past investigations suggested that the maximum cumulative dose at the hypocentre from immediately after the bombing until today is 0.8 Gy in Hiroshima and $0.3-0.4$ Gy in Nagasaki. When the distance is $0.5 \mathrm{~km}$ or $1.0 \mathrm{~km}$ from the hypocentre, the estimates are about $1 /$ 10 and 1/100 of the value at the hypocentre, respectively." The issue was examined in detail in the DS86 Final Report Chapter 6 and an Appendix to this Chapter [8]. The cumulative dose from induced radioactivity decreases exponentially with distance from the hypocentre.
From the DS02 dataset, the minimum distance from the hypocentre amongst cells with DS86 doses below $20 \mathrm{mSv}$ is $2.081 \mathrm{~km}$ while for cells with DS86 doses below 500 $\mathrm{mSv}$ it is $1.210 \mathrm{~km}$. For the $5-500 \mathrm{mSv}$ range the total cumulative impact of induced radioactivity would be below $8 \mathrm{mSv}$ in Hiroshima and below $4 \mathrm{mSv}$ in Nagasaki. Consider the unlikely possibility that induced radioactivity adds $8 \mathrm{mSv}$ to those cells which contain Hiroshima liver cancer deaths, and $4 \mathrm{mSv}$ to those cells which contain Nagasaki liver cancer deaths, while leaving all other cells unaffected. Under this extreme assumption, the twophase model at latency $\phi=36.9$ years has solutions with $\mathrm{ERR}_{1}<0$ but the linear model gives $\mathrm{LRT}_{\text {lin-con }}=11.03(1$ df) and $E R_{1}=0.029(0.010,0.054)$. Conversely, suppose that induced radioactivity adds $8 \mathrm{mSv}$ to those Hiroshima cells which do not contain liver cancer deaths, and $4 \mathrm{mSv}$ to those Nagasaki cells which do not contain liver cancer 
Table 5: Comparison with extrapolations from LSS $12^{a}$

\begin{tabular}{|c|c|c|c|c|c|c|}
\hline Site & gen & 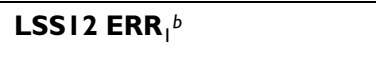 & 2-p ERR $\mathbf{R}_{1, \phi}{ }^{c}$ & $\phi_{\mathbf{m}}^{d}$ & trans $\mathbf{E R R}_{\mathrm{I}, \phi}^{\mathrm{e}}$ & $\phi_{\mathbf{m}}^{f}$ \\
\hline \multirow[t]{3}{*}{ Stomach } & $M / F$ & $0.0024(0.001,0.004)$ & $0.46(0.11,0.94)$ & 11.89 & $0.00(-0.06,0.16)$ & 11.85 \\
\hline & M & $0.001(-0.0005,0.0028)$ & $2.68(-0.15,32.45)$ & 6.14 & $0.00(-0.21,0.17)$ & 21.77 \\
\hline & $\mathrm{F}$ & $0.0047(0.0022,0.0077)$ & $0.80(0.15,1.77)$ & 13.67 & $0.43(0.00,0.96)$ & 13.68 \\
\hline \multirow[t]{3}{*}{ Liver } & $M / F$ & $0.0037(0.0013,0.0065)$ & $1.43(0.48,2.95)$ & 36.90 & $0.95(0.28,1.99)$ & 36.90 \\
\hline & M & $0.0048(0.0017,0.0088)$ & $1.72(0.40,4.25)$ & 36.97 & $1.30(0.28,3.10)$ & 36.97 \\
\hline & $\mathrm{F}$ & $0.0019(-0.0011,0.0062)$ & $1.24(0.06,3.60)$ & 36.90 & $1.09(0.15,2.78)$ & 38.55 \\
\hline \multirow[t]{3}{*}{ Lung } & $M / F$ & $0.0053(0.0028,0.0084)$ & $0.88(0.12,3.36)$ & 13.60 & $0.80(0.19,1.99)$ & 13.60 \\
\hline & $M$ & $0.0034(0.0006,0.0069)$ & $0.78(-0.11,4.91)$ & 13.55 & $0.74(0.05,2.40)$ & 13.55 \\
\hline & $\mathrm{F}$ & $0.0089(0.004 \mathrm{I}, 0.0 \mathrm{I} 5 \mathrm{I})$ & $1.35(0.07,4.83)$ & 21.91 & $1.04(0.09,3.28)$ & 21.91 \\
\hline \multirow{3}{*}{ Colon } & $M / F$ & $0.0065(0.0023,0.0121)$ & $0.05(-0.53,1.15)$ & 20.28 & $0.07(-0.49, \mathrm{I} .7 \mathrm{I})$ & 43.98 \\
\hline & M & $0.0048(-0.0002,0.0127)$ & $0.30(-0.59,3.16)$ & 28.63 & $0.40(-0.50,2.72)$ & 28.63 \\
\hline & $\mathrm{F}$ & $0.008 \mathrm{I}(0.0022,0.0077)$ & $0.47(-0.55,2.96)$ & 41.62 & $0.29(-0.78,2.26)$ & 41.62 \\
\hline Uterus & $\mathrm{F}$ & $0.0024(-0.0006,0.0067)$ & $0.47(-0.32,2.12)$ & 26.91 & $0.000(-0.23,1.06)$ & 26.91 \\
\hline Site & gen & LSS I 2 ERR $_{0.025^{b}}$ & 2-p $\mathbf{E R}_{0.025, \phi^{c}}$ & $\phi_{\mathbf{m}}^{d}$ & trans $\mathbf{E R}_{0.025, \phi^{d}}$ & $\phi_{\mathbf{m}}^{f}$ \\
\hline \multirow[t]{3}{*}{ Stomach } & $M / F$ & $0.00006(0.000025,0.000 I)$ & $0.39(0.08,0.86)$ & 11.89 & $0.08(-0.11,0.23)$ & 11.85 \\
\hline & $M$ & $0.001(-0.0005,0.0028)$ & $2.43(-0.23,31.08)$ & 6.14 & $0.16(-0.16,0.47)$ & 21.77 \\
\hline & $\mathrm{F}$ & $0.0047(0.0022,0.0077)$ & $0.71(0.05,1.62)$ & 13.67 & $0.30(0.01,0.76)$ & 13.68 \\
\hline \multirow[t]{3}{*}{ Liver } & $M / F$ & $0.000093(0.000033,0.00016)$ & $1.10(0.26,2.37)$ & 36.90 & $0.77(0.18,1.67)$ & 36.90 \\
\hline & M & $0.00012(0.000043,0.00022)$ & $1.30(0.12,3.50)$ & 36.97 & $1.25(0.25,3.00)$ & 36.97 \\
\hline & $\mathrm{F}$ & $0.000048(-0.000028,0.00016)$ & $1.03(0.04,2.94)$ & 36.90 & $0.43(0.01,1.46)$ & 38.55 \\
\hline \multirow[t]{3}{*}{ Lung } & $M / F$ & $0.00013(0.00007,0.00021)$ & $0.86(0.14,3.34)$ & 13.60 & $0.79(0.20,2.01)$ & 13.60 \\
\hline & $M$ & $0.000085(0.000015,0.000 \mid 4)$ & $0.96(-0.05,5.39)$ & 13.55 & $0.92(0.12,2.92)$ & 13.55 \\
\hline & $\mathrm{F}$ & $0.00022(0.0001,0.00038)$ & $1.12(0.08,4.15)$ & 21.91 & $0.91(0.10,2.87)$ & 21.91 \\
\hline \multirow[t]{3}{*}{ Colon } & $M / F$ & $0.00017(0.00006,0.0003)$ & $0.25(-0.44,1.46)$ & 20.28 & $0.58(-0.25,1.85)$ & 43.98 \\
\hline & $M$ & $0.00012(-0.000005,0.00032)$ & $0.65(-0.45,4.34)$ & 28.63 & $0.72(-0.30,3.72)$ & 28.63 \\
\hline & $\mathrm{F}$ & $0.0002(0.000055,0.00019)$ & $0.94(-0.21,3.17)$ & 41.62 & $0.85(-0.15,2.56)$ & 41.62 \\
\hline Uterus & $\mathrm{F}$ & $0.00006(-0.000015,0.00017)$ & $0.66(-0.10,2.44)$ & 26.91 & $0.25(-0.09,1.13)$ & 26.91 \\
\hline
\end{tabular}

a Life Span Study Report 12 [4]

$b$ from LSSI2 Tables All, Alll and AIV, scaled by the linear assumption ERR $=$ ERR per $10 \mathrm{mSv}=0.01$ (ERR per Sv) and $\mathrm{ERR}_{0.025}=0.00025(\mathrm{ERR}$ per Sv)

c Two-phase model fitted to $0-20 \mathrm{mSv}$ subcohort at optimal latency (see also Table 3 for M/F results)

d Optimal latency for Two-phase model on $0-20 \mathrm{mSv}$ subcohort

e Transient model at fitted to $0-20 \mathrm{mSv}$ subcohort at optimal latency (see also Table 2 for M/F results)

f Optimal latency for Transient model on $0-20 \mathrm{mSv}$ subcohort

deaths, while leaving all other cells unaffected. Then the linear model at latency $\phi=36.9$ years gives $\mathrm{LRT}_{\text {lin-con }}=$ $4.63(1 \mathrm{df})$ and $\mathrm{ERR}_{1}=0.016(0.001,0.036)$, which is still 4.3 times higher than the LSS12 estimate. These two extreme assumptions may perhaps provide limits on the scope for induced radioactivity to affect the linear model in the $5-500 \mathrm{mSv}$ subcohort, where the corresponding results without the addition of induced radioactivity are $\mathrm{LRT}_{\text {lin-con }}=7.25(1 \mathrm{df})$ and $\mathrm{ERR}_{1}=0.021(0.005,0.044)$. For the $0-20 \mathrm{mSv}$ dose range the total cumulative impact of induced radioactivity would be below $0.08 \mathrm{mSv}$ in Hiroshima and below $0.04 \mathrm{mSv}$ in Nagasaki. Whatever consequence this may have for the two-phase model, its effect on the linear model is negligible.

"Black rain" fell primarily at some distance from the hypocentres. According to the RERF website, "Because of wind, the rain mainly fell in northwestern Hiroshima (Koi-
Takasu area) and in eastern Nagasaki (Nishiyama area). The maximum estimates of dose due to fallout are 0.010.03 Gy in Hiroshima and 0.2-0.4 Gy in Nagasaki. The corresponding doses at the hypocentres are believed to be only about $1 / 10$ of these values." According to Chapter 6 of the DS86 Final Report [8] the rainfall was concentrated around $3000 \mathrm{~m}$ from the hypocentres in both cities. From the DS02 dataset, the maximum distance from the hypocentre amongst cells with DS86 doses above $5 \mathrm{mSv}$ is $2.683 \mathrm{~km}$, somewhat closer to the hypocentres than the main rainfall areas. Maximum doses from rainfall were much lower in Hiroshima, though RERF do not give enough detail to estimate an upper bound for the dose from "black rain" in Hiroshima at distances below 2.683 $\mathrm{km}$. However, if the Hiroshima data for the liver is analysed separately for the $5-500 \mathrm{mSv}$ subcohort, the twophase model remains a significant improvement over the linear model at latency $\phi=36.9$. LRT $_{2 \mathrm{p}-\text {-lin }}=5.718(1 \mathrm{df})$ 
Table 6: Two-phase and linear models fittted to subsets of the liver data ${ }^{a}$

\begin{tabular}{llllll}
\hline $\mathbf{i}$ & $\mathbf{R}_{\mathbf{i}}{ }^{b}$ & $\mathbf{p}-\mathbf{y}$ in $\mathbf{S}_{\mathbf{i}}{ }^{c}$ & Cases $^{d}$ & LRT $^{\mathrm{e}}$ & ERR $_{\mathbf{I}}{ }^{f}$ \\
\hline 1 & $0-0.01552$ & 1522195.93 & 441 & 22.00 & 1.67 \\
2 & $0.015521-0.019389$ & 1520822.41 & 459 & 18.94 & 1.28 \\
3 & $0.19396-0.022682$ & 1521452.84 & 499 & 27.01 & 1.49 \\
4 & $0.022687-0.025616$ & 1521872.88 & 500 & 30.31 & 1.57 \\
5 & $0.025619-0.30046$ & 1521932.58 & 510 & 28.61 & 1.42 \\
6 & $0.030066-0.037161$ & 1522215.36 & 494 & 26.14 & 1.37 \\
7 & $0.037211-0.87187$ & 1521303.24 & 483 & 26.31 & 1.50 \\
8 & $0.87209-0.97152$ & 1521034.77 & 492 & 30.44 & 1.36 \\
9 & $0.97154-1.0107$ & 1521559.95 & 507 & 28.56 & 1.74 \\
10 & $1.0108-2.000$ & 1519135.79 & 475 & 26.42 & 1.21 \\
\hline
\end{tabular}

\footnotetext{
$a$ The two-phase and linear models are fitted to subsets of the $0-20 \mathrm{mSv}$ liver data with latency $\phi=36.90$ years (optimal for the two-phase model on the $0-20 \mathrm{mSv}$ data, see Table 3)

${ }^{b} R_{i}$ is the excluded dose range (in $10 \mathrm{mSv}$ units). $S_{i}$ consists of those cells in the $0-20$ mSv subcohort whose weighted adjusted colon dose does not fall in $R_{i}$

c Person-years in $S_{i}$

${ }^{\mathrm{d}}$ Cases (liver cancer deaths) in $\mathrm{S}_{\mathrm{i}}$

$\mathrm{e} L R T=L R T_{2 \mathrm{p}-\text { lin }}$ for comparing the two-phase model with the linear model when fitted to $\mathrm{S}_{\mathrm{i}}$ with latency $\phi=36.90$ years

$f E R R_{1}$ is the estimated Excess Relative Risk at $10 \mathrm{mSv}$ when the two-phase model with latency $\phi=36.90$ years is fitted to $S_{i}$
}

and $\mathrm{ERR}_{1}=0.674(-0.06,1.92)$ while for the linear model $\mathrm{LRT}_{\text {lin-con }}=7.946$ and $\mathrm{ERR}_{1}=0.027(0.007,0.055)$.

Compounding the uncertainty over doses from "black rain", individuals may have travelled into a rainfall area even if they were outside it when the bombs exploded. RERF's estimates refer to external doses, omitting any inhaled or ingested radiation. In any case the conclusions are provisional until a dataset for specific solid cancers showing DS02 flash doses, induced radioactivity and "black rain" becomes available. Potential confounding by other risk factors cannot be excluded. The neutron RBE of 10 used here, as in LSS12 and elsewhere, may be inappropriate. Despite all these reservations, which also affect the LSS studies, it is striking that both the $0-20 \mathrm{mSv}$ and 5 $500 \mathrm{mSv}$ subcohorts show non-linear dose response for the liver and the two-phase model gives comparable estimates from both subcohorts for Excess Relative Risk at 10 mSv with latency 36.9 years. "Black rain" and induced radioactivity have quite different impacts within these two subcohorts.

I do not know whether these results and the optimal latencies are specific to the A-bomb cohort. In their study of gamma radiation and mortality in the Oak Ridge workforce, Frome et al. [18] find a 'Low-dose $\beta$ ' value of 2.9 with LRT $=3.12(p=0.08)$ for the combined digestive category using a multiplicative model (without latency) with dose restricted to $0-640 \mathrm{mSv}$. Since their unit dose is 1 $\mathrm{Sv}$ this corresponds to $\mathrm{ERR}_{1}=0.029$.

Non-linear models are applied here without assuming any cellular mechanism, and their success in fitting the cohort data does not prove that any particular cell mechanism operated there. However, the two-phase model adapts and simplifies a model derived by Brenner et al. [19] to explain the 'oncogenic transformation frequency' of cells exposed to broad beam irradiation by $\alpha$ particles:

$$
\mathrm{TF}=v \mathrm{q}<\mathrm{N}>+\sigma\left[1-\mathrm{e}^{(-\mathrm{k}<\mathrm{N}>)}\right]\left[e^{(-\mathrm{q}<\mathrm{N}>)}\right]
$$

TF is the number of transformed cells per surviving cell (Excess Relative Risk of transformation); $v$ is the transformation frequency for cells struck directly by exactly one $\alpha$ particle, q the surviving fraction of cells struck directly by exactly one $\alpha$ particle, $<\mathrm{N}>$ the mean number of $\alpha$ particles striking each cell in the broad beam irradiation (a dose variable), $\mathrm{k}$ the number of cells receiving the bystander signal emitted from a cell struck directly by one or more $\alpha$ particles, and $\sigma$ the (presumed) hypersensitive fraction of bystander cells which are transformed on receipt of any bystander signal. Note that the first term in the TF expression refers to direct effects, whilst the second term refers to bystander effects. As a function of $\langle\mathrm{N}\rangle, \mathrm{TF}$ is approximately linear with slope $v \mathrm{q}+\sigma \mathrm{k}$ at very low doses and approximately linear with slope $v \mathrm{q}$ at higher doses.

The two-phase model is asymptotically linear with slope $\sigma+\beta$ at very low doses and asymptotically linear with slope $\beta$ at higher doses. It generates curves of the same qualitative shape as the TF cell model.

In the cell model, the ratio of asymptotic slopes is $\mathbf{R}=$ $1+(\sigma \mathrm{k} / \mathrm{v} \mathrm{q})$. From targetted microbeam experiments on $\mathrm{C} 3 \mathrm{H} 10 \mathrm{~T}^{1} / 2$ mouse fibroblast cells, Brenner et al. estimate $v=1.3 \times 10^{-4}, \sigma=6.4 \times 10^{-4}$, and $\mathrm{q}=0.8$. Thus $\mathbf{R} \sim 1+6.2$ k. In a subsequent paper Brenner and Sachs [20] suggest that $\mathrm{k} \sim 50$ (so $\mathbf{R} \sim 311$ ) for the human lung, from modelling dose-rate effects in (male) uranium miners exposed to radon. 
In the two-phase model, the ratio of asymptotic slopes is $\mathbf{R}=1+\sigma / \beta$. For the male lung, with optimal latency 13.55 years, $\mathbf{R}=202.22$. For the lung, the two-phase model is not significant against the transient and the confidence region for $\mathbf{R}$ is infinite and includes negative values. But for the stomach (M/F) $\mathbf{R}=262.62$ with $95 \%$ CI (102.41, 975.09), and for the liver (M/F) $\mathbf{R}=204.11$ (58.29, 792.85). Thus the low dose A-bomb data is compatible with a bystander model using roughly comparable values of $k$, the number of cells receiving the bystander signal.

The flash dose comprised gamma and neutron doses. An appropriate cell model for bystander effects following gamma radiation may differ from that developed for $\alpha$ particles, where the impact of a single track on one cell is quite large. However fission neutrons, like $\alpha$ particles, are high LET (linear energy transfer) and might elicit a similar bystander signal. Induction of genomic instability in unirradiated bystander cells has been demonstrated for neutron irradiation in mice [21].

Non-linear dose response curves can also arise from a hypersensitive population subset [22]. Sharp et al. [23] analysed primary liver cancer mortality in relation to Hepatitis B and C in Japanese A-bomb survivors and found a very strong supermultiplicative interaction between HVC and radiation dose, but only for the high and medium dose ranges. For doses below $18 \mathrm{mSv}$, there was no significant interaction. However, Sharp et al. did not include latency and truncated all liver doses below $3 \mathrm{mSv}$. I could not analyse primary liver cancer because the data in r12canc.dat shows all liver cancers. Persistent inflammation including chronic liver disease has been detected in Japanese survivors 40 years after the bombing and correlated with radiation dose [24].

\section{Conclusion}

All the models considered here show unexpectedly large and significant results in the $0-20 \mathrm{mSv}$ dose range when a lagged colon dose is taken as the main predictor. Nonlinear models allowing for asymptotic effects as dose approaches 0 improve the fit and give a much higher slope for the dose response curve near 0 than at higher doses.

Whether or not analyses of this cohort can be transferred internationally, the results here raise questions in Japan. In any case, significant results for doses below $20 \mathrm{mSv}$ are directly relevant to the current ICRP recommendations limiting annual occupational exposure to $20 \mathrm{mSv}$ (whole body dose). Analysis of the $0-20 \mathrm{mSv}$ dose range gives responses several orders of magnitude above extrapolations from LSS12 (and other Life Span Studies).

Low dose effects which depend on latency or are detected by non-linear models can still cause significant risks.

\section{Declaration of competing interests}

The author(s) declare that they have no competing interests.

\section{Authors' contributions}

GD conceived of and designed the study and carried out the statistical analysis.

\section{Acknowledgements}

Special thanks to David Richardson for extended correspondence and suggesting the latency parameter approach, Steve Wing for raising dosimetry questions during peer review, and Tom Sorahan for comments on a draft. Thanks also to Dale Preston, John Cologne, Mike Thorne, Keith Baverstock, David Brenner, Beate Ritz, Teresa Coons, Rudi Nussbaum, Joe Abramson, and Ric Swindell for comments, criticism and encouragement at earlier stages.

This work was not funded.

The data described in this report were obtained from the Radiation Effects Research Foundation (RERF) in Hiroshima, Japan via the Comprehensive Epidemiologic Data Resource. RERF is a private foundation that is funded equally by the Japanese Ministry of Health and Welfare and the US Department of Energy through the US National Academy of Sciences. The conclusions reached in this report are mine and do not necessarily reflect the scientific judgement of RERF or its funding agencies.

\section{References}

I. Committee on the Biological Effects of lonizing Radiations (CBEIR): Health Effects of Exposure to Low Levels of lonizing Radiation - BEIR V Washington, D.C.; 1990.

2. ICRP: 1990 Recommendations of the International Commission on Radiological Protection Publication 60, Annals of the ICRP 2 I (I-3) Oxford; 1991.

3. Nussbaum RH: The linear no-threshold dose-effect relation: is it relevant to radiation protection legislation? Med Phys 1998, 25(3):29I-299.

4. Pierce DA, Shimizu Y, Preston DL, Vaeth M, Mabuchi K: Studies of the Mortality of Atomic Bomb Survivors. Report I2, Part I, Cancer: 1950-1990. Radiat Res 1996, I46(I): I-27.

5. Mothersill C, Seymour C: Radiation-induced bystander effects: past history and future directions. Radiat Res 200I, I 55(6):759-767.

6. RERF (Radiation Effects Research Foundation) [http:// www.rerf.or.jp/]

7. CEDR (Comprehensive Epidemiologic Data Resource) Data File Set JALSSA03 File ID: RI2CANC [http://cedr.lbl.gov/cgibin/spiface/find/cedrfile/?FILE = 1040]. accessed I 9 September 2002

8. US-Japan Joint Reassessment of Atomic Bomb Radiation Dosimetry in Hiroshima and Nagasaki (DS86): Volume I and Volume 2 [http://www.rerf.or.jp/shared/ds86/ds86a.html]. http:// www.rerf.or.jp/shared/ds86/ds86b.html

9. DS02 Risk Estimation: Solid Cancer and Leukemia Mortality Data [http://www.rerf.or.jp/eigo/scidata/ds02.htm]

10. Preston DL, Pierce DA, Shimizu Y, Cullings HM, Fujita S, Funamoto S, Kodama K: Effect of recent changes in atomic bomb survivor dosimetry on cancer mortality risk estimates. Radiat Res 2004, 162(4):377-89.

II. Cullings HM, Fujita S, Funamoto S, Grant EJ, Kerr GD, Preston DL: Dose estimation for atomic bomb survivor studies: its evolution and present status. Radiat Res 2006, 166 (I Pt 2):219-54.

12. Breslow NE, Day NE: Statistical methods in cancer research. Volume II The design and analysis of cohort studies. IARC Sci Publ 1987: I-406.

13. Rothman KJ: Induction and latent periods. Am J Epidemiol I98I, I I 4(2):253-259.

14. Committee on the Biological Effects of lonizing Radiations (CBEIR): Health Risks of Radon and Other Internally Deposited Alpha-Emitters BEIR IV Washington, D.C.; 1988. 
15. Langholz B, Thomas D, Xiang A, Stram D: Latency analysis in epidemiologic studies of occupational exposures: application to the Colorado plateau uranium miners cohort. Am J Ind Med 1999, 35(3):246-256.

16. Stewart AM, Kneale GW: A-bomb survivors: factors that may lead to a re-assessment of the radiation hazard. Int J Epidemiol 2000, 29(4):708-7|4

17. Pierce DA, Preston DL: Radiation-Related Cancer Risks at Low Doses among Atomic Bomb Survivors. Radiat Res 2000, I54(2): $178-186$

18. Frome EL, Cragle DL, Watkins JP, Wing S, Shy CM, Tankersley WG, West CM: A mortality study of employees of the nuclear industry in Oak Ridge, Tennessee. Radiat Res 1997, I 48(I):64-80.

19. Brenner DJ, Little JB, Sachs RK: The bystander effect in radiation oncogenesis: II. A quantitative model. Radiat Res 200I, I 55(3):402-408

20. Brenner DJ, Sachs RK: Do low dose-rate bystander effects influence domestic radon risks? Int J Radiat Biol 2002, 78(7):593-604.

21. Watson GE, Lorimore SA, Macdonald DA, Wright EG: Chromosomal instability in unirradiated cells induced in vivo by a bystander effect of ionizing radiation. 2000, 60(20):5608-II.

22. Baum JW: Population heterogeneity hypothesis on radiation induced cancer. Health Phys 1973, 25(2):97-104.

23. Sharp GB, Mizuno T, Cologne JB, Fukuhara T, Fujiwara S, Tokuoka S, Mabuchi K: Hepatocellular carcinoma among atomic bomb survivors: significant interaction of radiation with hepatitis $\mathbf{C}$ virus infections. Int J Cancer 2003, I03(4):53I-537.

24. Neriishi K, Nakashima E, Delongchamp RR: Persistent subclinical inflammation among A-bomb survivors. Int J Radiat Biol 200I, 77(4):475-82.

Publish with Bio Med Central and every scientist can read your work free of charge

"BioMed Central will be the most significant development for disseminating the results of biomedical research in our lifetime. "

Sir Paul Nurse, Cancer Research UK

Your research papers will be:

- available free of charge to the entire biomedical community

- peer reviewed and published immediately upon acceptance

- cited in PubMed and archived on PubMed Central

- yours - you keep the copyright

Submit your manuscript here:

http://www.biomedcentral.com/info/publishing_adv.asp
BioMedcentral 